\title{
Pitfalls in the neuroimaging of glioblastoma in the era of antiangiogenic and immuno/targeted therapy - detecting illusive disease, defining response
}

\section{Raymond Y. Huang*, Martha R. Neagu, David A. Reardon and Patrick Y. Wen}

Center of Neuro-Oncology, Dana-Farber/Brigham and Women's Cancer Center, Boston, MA, USA

\section{Edited by:}

Pamela Zyman New, The Methodist Hospital Neurological Institute, USA

Reviewed by:

Johan Pallud, Université Paris

Descartes, France

David D. Eisenstat, University of

Alberta, Canada

*Correspondence:

Raymond Y. Huang, Department of Radiology, Brigham and Women's

Hospital, 75 Francis Street, Boston, MA 02115, USA

e-mail:ryhuang@partners.org
Glioblastoma, the most common malignant primary brain tumor in adults is a devastating diagnosis with an average survival of 14-16 months using the current standard of care treatment. The determination of treatment response and clinical decision making is based on the accuracy of radiographic assessment. Notwithstanding, challenges exist in the neuroimaging evaluation of patients undergoing treatment for malignant glioma. Differentiating treatment response from tumor progression is problematic and currently combines long-term follow-up using standard magnetic resonance imaging (MRI), with clinical status and corticosteroid-dependency assessments. In the clinical trial setting, treatment with gene therapy, vaccines, immunotherapy, and targeted biologicals similarly produces MRI changes mimicking disease progression. A neuroimaging method to clearly distinguish between pseudoprogression and tumor progression has unfortunately not been found to date. With the incorporation of antiangiogenic therapies, a further pitfall in imaging interpretation is pseudoresponse. The Macdonald criteria that correlate tumor burden with contrast-enhanced imaging proved insufficient and misleading in the context of rapid bloodbrain barrier normalization following antiangiogenic treatment that is not accompanied by expected survival benefit. Even improved criteria, such as the RANO criteria, which incorporate non-enhancing disease, clinical status, and need for corticosteroid use, fall short of definitively distinguishing tumor progression, pseudoresponse, and pseudoprogression. This review focuses on advanced imaging techniques including perfusion MRI, diffusion $\mathrm{MRI}, \mathrm{MR}$ spectroscopy, and new positron emission tomography imaging tracers. The relevant image analysis algorithms and interpretation methods of these promising techniques are discussed in the context of determining response and progression during treatment of glioblastoma both in the standard of care and in clinical trial context.

Keywords: glioblastoma, pseudoprogression, pseudoresponse, antiangiogenic therapy, Immunotherapy, imaging techniques

\section{CURRENT CHALLENGES IN POST-TREATMENT IMAGING OF GLIOBLASTOMA}

Glioblastoma, the most common malignant primary tumor of the central nervous system, carries a dismal prognosis with an average median survival of $14-16$ months $(1,2)$. This has remained largely unchanged in the last decades, despite increased understanding of molecular pathogenesis and tumor microenvironment $(3,4)$. The current standard of care for newly diagnosed GBM consists of maximal safe resection followed by $60 \mathrm{~Gy}$ fractionated radiotherapy plus continuous daily temozolomide and then 6-12month cycles of adjuvant temozolomide $(5,6)$. At progression, bevacizumab is the mainstay of treatment, more recently with the addition of CCNU (7).

Therapeutic strategies to date include intensified chemotherapy regimens, targeting distinct molecular pathways, inhibiting angiogenesis, and more recently immunotherapy (8). Despite these efforts, very few agents have been approved for the treatment of glioblastoma aside from temozolomide for patients with newly diagnosed GBM and bevacizumab for patients with progressive disease (PD) $(5,9)$. The molecular and biological complexity of GBM, its inherent adaptability and poor response to treatment, redundancy of signaling pathways, as well as the poor penetration of therapeutic agents through the blood-brain barrier (BBB) all contribute to poor progress in approval of effective therapeutics (9). A major road-block to assessment and development of effective therapeutics, however, is the lack of reliable trial endpoints (9). While overall survival (OS) is the gold standard in assessment of efficacy, progression-free survival (PFS) and response rate (RR) are valuable endpoints, highlighting the relative benefit of a given therapy and facilitating effective drug development $(6,10)$. Response and progression endpoints rely on magnetic resonance imaging (MRI) and are fraught with challenges including variability in image acquisition parameters, inter-rater measurement variability, difficulty in measurement of irregularly shaped tumors, and consistent interpretation of treatment-related radiographic changes: pseudoprogression secondary to radiation and chemotherapy, as well as pseudoresponse with antiangiogenic therapy $(6,9)$. 
Current radiographic assessment of glioblastoma is based on MRI, with extent of tumor burden assessed by appearance of enhancement on contrast-enhanced T1-weighted images. This is due to local breakdown of the BBB secondary to angiogenesis in aggressive tumors (11). Response criteria developed by Macdonald et al. (12) improved on previous radiologic assessments of tumors, such as the World Health Organization response criteria, by combining bi-directional measures of enhancing tumor burden with clinical parameters, such as corticosteroid use and neurological status (13). The Macdonald criteria classify response into four categories: complete response (CR), partial response (PR; $\geq 50 \%$ decrease in the sum of the products of perpendicular diameters of all measurable enhancing lesions sustained for at least 4 weeks, and stable or improved clinically), stable disease (SD), and PD ( $\geq 25 \%$ increase in sum of products of perpendicular diameters of enhancing lesion or clinical deterioration) (Table 1) (12).

\section{Table 1 | Current response criteria for malignant gliomas (Macdonald} criteria).

\begin{tabular}{|c|c|}
\hline Response & Criteria \\
\hline $\begin{array}{l}\text { Complete } \\
\text { response }\end{array}$ & $\begin{array}{l}\text { Requires all of the following: complete disappearance of } \\
\text { all enhancing measurable and non-measurable disease } \\
\text { sustained for at least } 4 \text { weeks, no new lesions, no } \\
\text { corticosteroids, and stable or improved clinically }\end{array}$ \\
\hline $\begin{array}{l}\text { Partial } \\
\text { response }\end{array}$ & $\begin{array}{l}\text { Requires all of the following: } \geq 50 \% \text { decrease compared } \\
\text { with baseline in the sum of products of perpendicular } \\
\text { diameters of all measurable enhancing lesions sustained } \\
\text { for at least } 4 \text { weeks, no new lesions, stable or reduced } \\
\text { corticosteroid dose, and stable or improved clinically }\end{array}$ \\
\hline $\begin{array}{l}\text { Stable } \\
\text { disease }\end{array}$ & $\begin{array}{l}\text { Requires all of the following: does not qualify for complete } \\
\text { response, partial response, or progression; and stable } \\
\text { clinically }\end{array}$ \\
\hline Progression & $\begin{array}{l}\text { Defined by any of the following: } \geq 25 \% \text { increase in sum of } \\
\text { the products of perpendicular diameters of enhancing } \\
\text { lesions, any new lesion, or clinical deterioration }\end{array}$ \\
\hline
\end{tabular}

Reprinted with permission from Ref. (6).
In 2010, in an effort to improve radiographic response criteria in an era of new biologicals and increasing need for guidelines regarding patients enrolling in clinical trials, the Response Assessment in Neuro-Oncology (RANO) Working Group proposed updated response criteria for high-grade gliomas (6) (Table 2). Increasingly, T2-weighted imaging had been incorporated into clinical practice and is particularly useful in visualizing vasogenic edema, gliosis, chemoradiation-related treatment effects, as well as evolving infiltrative and non-enhancing tumor in an era of antiangiogenic therapies that directly alter BBB permeability (14) (Table 2). Another important advance of the RANO criteria was addressing and defining pseudoresponse and pseudoprogression (6).

\section{PSEUDOPROGRESSION}

The standard of care in glioblastoma treatment involves maximal safe resection followed by radiation with adjuvant temozolomide $(5,6)$. Within 3 months from end of radiation treatment, $20-30 \%$ of patients show increased contrast enhancement that resolves without changes in treatment on subsequent MRI scans (6). This phenomenon termed "pseudoprogression" is likely related to enhanced inflammation and disruption of the BBB caused by radiation itself, potentially enhanced by concurrent temozolomide use (6). While the pathophysiology of pseudoprogression remains to be elucidated, it seems to be part of a spectrum of radiationrelated changes ranging from subacute radiographic changes to late radionecrosis (15). Pseudoprogression has also been reported in interstitial chemotherapy with carmustine-loaded polymers, which is a therapeutic option in both newly diagnosed (16-18) and progressive $(19,20)$ high-grade gliomas. In patients implanted with carmustine wafers, there is a high incidence (up to $90 \%$ ) of cyst development near the surgical bed $(21,22)$ as well as a transient increase in contrast enhancement and peri-cavity edema within the first 2 months after wafer placement (23).

Failure to recognize pseudoprogression may lead to premature discontinuation of effective adjuvant temozolomide chemotherapy and inappropriate inclusion of these patients into trials for progressive/recurrent glioma, resulting in falsely elevated RRs and PFS (6). The RANO criteria attempt to address this problem by excluding patients who "progress" during the first 12 weeks

Table 2 | Summary of the proposed RANO response criteria.

\begin{tabular}{|c|c|c|c|c|}
\hline Criterion & CR & PR & SD & PD \\
\hline T2/FLAIR & Stable or $\downarrow$ & Stable or $\downarrow$ & Stable or $\downarrow$ & $\uparrow^{a}$ \\
\hline Corticosteroids & None & Stable or $\downarrow$ & Stable or $\downarrow$ & $N A^{b}$ \\
\hline Clinical status & Stable or $\uparrow$ & Stable or $\uparrow$ & Stable or $\uparrow$ & $\downarrow^{a}$ \\
\hline
\end{tabular}

RANO, response assessment in neuro-oncology; $C R$, complete response; $P R$, partial response; $S D$, stable disease; PD, progressive disease; FLAIR, fluid-attenuated inversion recovery; $N A$, not applicable.

${ }^{a}$ Progression occurs when this criterion is present.

${ }^{b}$ Increase in corticosteroids alone will not be taken into account in determining progression in the absence of persistent clinical deterioration.

Reprinted with permission from Ref. (6), License Number 3484960750851 
post-chemoradiation from entry into new clinical trials unless the progression is largely outside the radiation field or if there is pathologic conformation of progressive/recurrent tumor (6). Despite these advances, pseudoprogression remains a significant diagnostic challenge, and this review will discuss the advanced imaging techniques that are currently being evaluated in differentiating pseudoprogression from true progression of glioblastoma.

\section{ADVANCED IMAGING TECHNIQUES FOR EVALUATION OF TREATMENT RESPONSE DIFFERENTIATING PSEUDOPROGRESSION FROM TUMOR PROGRESSION \\ Magnetic resonance perfusion imaging}

The hemodynamic characteristics of brain tumors and radiation necrosis can be estimated non-invasively using perfusion imaging techniques. Three magnetic resonance perfusion techniques are increasingly available on clinical MRI scanners: dynamic susceptibility contrast (DSC)-MRI, dynamic contrast enhanced (DCE)-MRI, and arterial spin labeling (ASL).

\section{Dynamic susceptibility contrast-magnetic resonance imaging}

Dynamic susceptibility contrast-magnetic resonance imaging measures the signal intensity change related to $\mathrm{T} 2 / \mathrm{T}^{*}{ }^{*}$ relaxation during a first-pass bolus of paramagnetic contrast agent $(24,25)$. Quantitative parameters derived from the time-intensity curve using normal brain as reference are used to depict pathological alterations. These include relative cerebral blood volume (rCBV), the most commonly studied parameter in DSC-MRI for characterization brain tumor (Figure 1), as well as relative peak height $(\mathrm{rPH})$ and percentage of signal intensity recovery (PSR) (26). These parameters can be normalized or standardized using normal gray and white matter for easier comparison between studies and patients $(27,28)$.

While a number of studies have applied DSC-MRI methods to distinguish pseudoprogression from tumor progression in glioblastoma, a wide range of sensitivity and specificity have been reported (29-34). These variations can result from small sample sizes in some of these studies as well as from differences in acquisition protocols, analytic techniques, and reference standards among the studies. Using histopathology from 57 patients as a reference standard, Barajas et al. demonstrated that $\mathrm{rPH}$ and rCBV were significantly greater in progressive/recurrent tumor as compared to radiation necrosis, while PSR values were significantly lower in patients with recurrent tumor (30). $\mathrm{rPH}$ also appears to be the best predictor of recurrent tumor compared to rCBV and PSR in this study, since the latter two parameters have significant overlaps between tumor tissue and radiation necrosis. Similarly, $\mathrm{Hu}$ et al. examined 40 stereotactic specimens from 13 patients and compared them with preoperative $\mathrm{rCBV}$ (31). With an rCBV threshold of 0.71 , pseudoprogression can be differentiated from progressive/recurrent tumor with a sensitivity of $91.7 \%$ and a specificity of $100 \%$ in this small series.

The role of histopathology as the standard reference for assessment of tumor progression versus radiation necrosis is increasingly being challenged; in addition to sampling error and reader variability, post-treatment tissues often contain both viable tumor and necrotic tissues making it difficult for all-or-none diagnoses. On the other hand, imaging approaches that take into account whole-tumor heterogeneity can mitigate this problem. $\mathrm{Hu}$ et al. developed the concept of MRI-fractional tumor burden (pMRIFTB) and demonstrated that this parameter correlated with the relative histologic fraction of viable tumor and was also predictive of OS (35). Analyzing perfusion maps from 79 patients with glioblastoma, Baek et al. demonstrated that histogram analysis of whole-tumor rCBV can help differentiate pseudoprogression from tumor progression with sensitivity of $85.7 \%$ and a specificity of 89.2\% (34).

Perfusion maps before and after chemoradiation therapy can be analyzed simultaneously as parametric response maps (34). A decrease in $\mathrm{rCBV}$ and $\mathrm{rCBF}$ on parametric response maps, counter-intuitively, is more often observed with progressive/recurrent tumor (36). Cao et al. also reported that a decrease

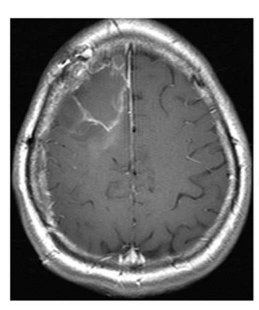

Post-op

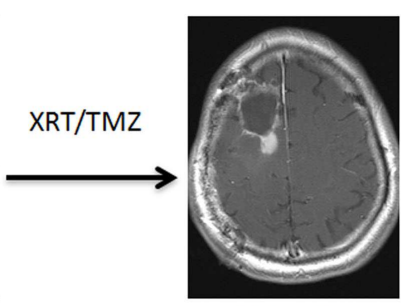

1 Month

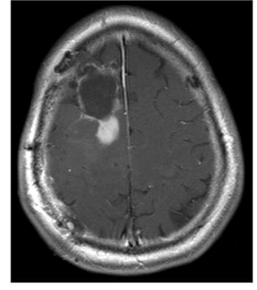

3 Month

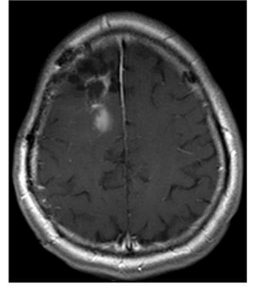

5 Month

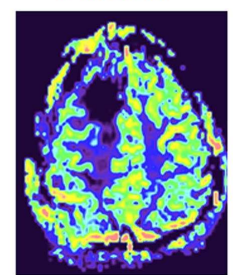

FIGURE 1 |A new enhancing lesion appeared around the resection cavity 1 month following completion of chemoradiation, without evidence of elevated rCBV on DSC-MRI. The lesion continued to grow during the next 2 months but eventually decreased in size, consistent with pseudoprogression. 
in fractional tumor volume with low rCBV 1 week following radiation was predictive of improved survival in 23 patients with high-grade gliomas (37). From the same study, it appears that the timing of rCBV measurement following radiation is important, since a decrease in the fractional high-CBV tumor volume in the third week versus in the first week following radiation was also predictive of a longer survival outcome. Mangla et al. have shown in 36 glioblastoma patients that an increased in percentage change of $\mathrm{rCBV}(>5 \%)$ after radiation and temozolomide was predictive of 1 -year survival with a sensitivity of $90 \%$ and a specificity of $60 \%(38)$.

While DSC-MRI has several advantages as a choice of perfusion imaging technique including ease of implementation, rapid acquisition, and an optimized signal-to-noise level, there are a number of technical limitations. Due to its sensitivity to susceptibility, the signal-to-noise level of DSC-MRI can be significantly reduced in anatomical areas near the bone or air interface, as well as near sites with significant blood products. The accuracy of rCBV can also be affected by the presence of $\mathrm{BBB}$ disruption resulting in T1-weighted leakage and T2/T2*-residual effects. The effect from contrast leakage can lead to either overestimation or underestimation of rCBV in tumors (39) (Figure 2). Several methods can be implemented to minimize the effect of contrast leakage permeability on rCBV calculation, including contrast preloading (40), dual-echo acquisition (41), and modeling of transvascular transfer constant (37, 42-45). Finally, blood-pool contrast agents, such as ferumoxytol, can reduce leakage effect; in patients with glioblastoma following chemoradiation, Gahramanov et al. demonstrated that $\mathrm{rCBV}$ calculated from DSC-MRI perfusion acquisition using ferumoxytol is predictive of OS without the need of leakage correction (46).

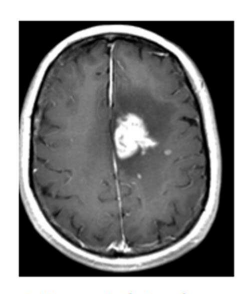

T1 weighted + contrast

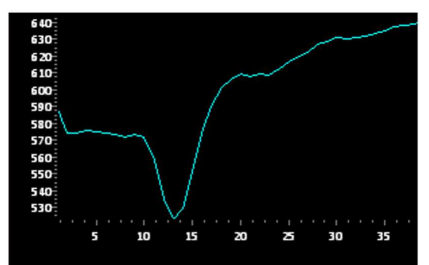

Signal intensity curve vs time (sec)

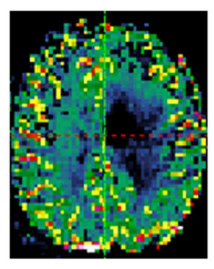

Uncorrected CBV

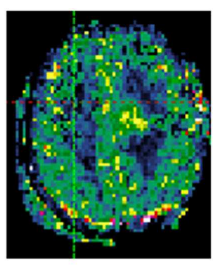

Corrected CBV
FIGURE 2 | New enhancing area in a patient with glioblastoma following chemoradiation treatment, with pathologically confirmed tumor progression. The uncorrected CBV map showed an apparently lower blood volume relative to normal brain. Presence of significant leakage is seen within the enhancing lesion as indicated by signal intensity curve and leakage map. Following leakage correction, elevated cerebral blood volume in the enhancing region is confirmed.

\section{Dynamic contrast enhanced-magnetic resonance imaging}

Dynamic contrast enhanced-magnetic resonance imaging techniques can characterize vascular permeability by quantifying movement of paramagnetic contrast agents crossing the $\mathrm{BBB}$ using pharmacokinetic models (47-49). The most widely studied variables derived from DCE-MRI in brain tumor imaging are Ktrans (transfer coefficient between the intra- and extravascular spaces), Ve (extravascular, extracellular space), and Kep (transfer constant from the extracellular, extravascular space into the plasma) $(48,49)$. Compared to DSC-MRI, DCE-MRI is relatively immune to susceptibility artifact and can more accurately account for contrast agent leakage effect in the calculation of cerebral blood volume. With T1-weighted image acquisitions, DCE-MRI derived perfusions maps also have greater signal-to-noise ratio and spatial resolution, although there is a need for longer imaging acquisition time.

Several studies have applied DCE-MRI to differentiate tumor progression from radiation necrosis (Figure 3). Larsen et al. reported nearly $100 \%$ sensitivity and specificity using calculated CBV, comparable to those determined by FDG-positron emission tomography (PET) on the same patients (50). Bisdas et al. demonstrated significant greater Ktrans in progressive/recurrent tumor lesions as compared to the radiation-induced necrotic sites $(P \leq 0.0184)$. A Ktrans cutoff value higher than 0.19 showed $100 \%$ sensitivity and $83 \%$ specificity for detecting progressive/recurrent gliomas (51).

Despite the advantages of DCE-MRI, the pharmacokinetic models for calculation of physiological parameters are typically complex and require several assumptions, leading to difficulty in standardization. Non-model-based methods are easier to implement and the resulting semiquantitative parameters, while not physiologic, are more reproducible. Narang et al. assessed nonmodel based parameters initial area under the signal intensitytime curve (iAUC) and maximum slope of enhancement in initial vascular phase (MSIVP) to help differentiate progressive/recurrent glioblastoma from radiation necrosis in 36 patients

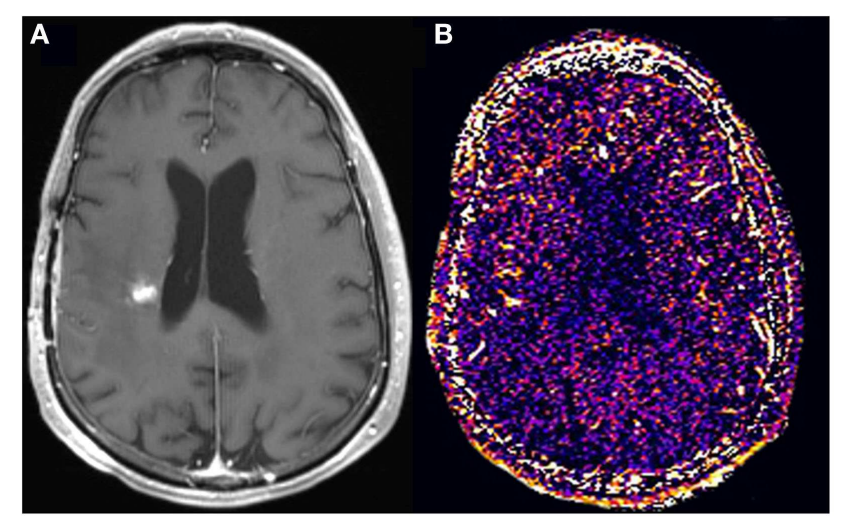

FIGURE 3 | A new enhancing lesion appeared adjacent to the resection cavity 3 months following completion of chemoradiation (A), without evidence of elevated kTrans (B) on DCE-MRI. The lesion remained unchanged in size for the subsequent 4 months, consistent with pseudoprogression. 
with glioblastoma (52). Significantly higher MSIVP and iAUC (at 60 and $120 \mathrm{~s}$ ) were observed in the progressive/recurrent tumor group, with MSIVP being the better single predictor with high sensitivity (95\%) and specificity (78\%).

In a larger retrospective cohort of 169 patients with pathologically or clinicoradiologically diagnosed progressive/recurrent glioblastoma $(n=87)$ or radiation necrosis $(n=82)$, Kim et al. demonstrated the addition of either DSC-MRI or DCE-MRI to contrast-enhanced T1-weighted and diffusion-weighted images improved prediction of progressive/recurrent tumor (53). However, there was no significant difference between DSC-MRI and DEC-MRI in the degree of improvement for diagnostic accuracy.

\section{Arterial spin label MR perfusion}

Arterial spin label (ASL) MR perfusion imaging estimates cerebral blood flow (CBF) by tagging endogenous blood as a flow tracer without the need of injecting exogenous contrast $(54,55)$. Although ASL is limited by lower signal intensity-to-noise ratio and longer acquisition time compared to DCE-MRI and DSCMRI, the major advantage of ASL technique is its application in patients with insufficient renal excretory function and the ability to repeat ASL acquisitions during a single study. This technique has been applied to imaging of glioma, and the blood flow measurement correlates with histologic grades $(56,57)$. Choi et al. retrospectively evaluated the added value of ASL to DSC-MRI in 177 consecutive patients with glioblastoma following standard chemoradiation therapy (58) (Figure 4). Among the 62 patients who developed contrast-enhancing lesions, ASL grading is an independent predictor of early tumor progression and improves diagnostic accuracy when interpreted qualitatively in conjunction with DSC-MRI.

The advantages and disadvantages of the three MR perfusion techniques discussed in this review are summarized in Table 3. The clinical value of perfusion imaging has been increasingly recognized in neuro-oncology centers as recently demonstrated by Geer et al. in their analysis of the contribution of perfusion imaging to clinical decision making (59). While the acquisition and analytic algorithms have improved significantly over the last decade, for perfusion to be incorporated into standard response criteria in clinical trials and routine clinical practice, significant improvements are still needed in standardizing perfusion protocols in order to increase diagnostic accuracy and reproducibility.

\section{Magnetic resonance diffusion imaging}

Magnetic resonance diffusion imaging can non-invasively examine tissue by probing microscopic water motion to indirectly assess cell density and architecture. When applied to brain tumors, diffusion imaging can assist in differentiating tumor type (60-64), as well as predicting tumor grade (65-68) and estimating prognosis (67). Most current clinical applications of diffusion imaging is performed with diffusion weighting factor $b$ near $1000 \mathrm{~s} / \mathrm{mm}^{2}$ where the diffusion signal decay is approximately mono-exponential. This single exponential constant, or apparent diffusion coefficient (ADC), can be readily calculated for each voxel and represented as a magnitude map. In brain tumor imaging, ADC has been shown to inversely correlate with tumor cell density $(64,65,69)$. With increased cellularity, ADC values tend to be lower for highgrade glial tumors, likely due to restricted water motion in the midst of tightly packed tumor cells (65). On the other hand, peritumoral edema is characterized by high $\mathrm{ADC}$ values $(60,70)$. Other pathological conditions can also result in alterations in ADC values including ischemia, infection or inflammation. Thus, diffusion-weighted imaging is often interpreted alongside other MR sequences to increase diagnostic specificity. One important cause of new or increased enhancement following chemoradiation is due to postsurgical infarction (71). Thus, examining diffusionweighted images of immediate postoperative MRI is important in making this diagnosis.

Several prior studies have demonstrated lower ADC values with respect to normal brain tissues in patients who received radiation and chemotherapy and had subsequently confirmed tumor progression (72-74) (Figure 5). Furthermore, an increase in tumor $\mathrm{ADC}$ values following therapy compared to pre-treatment ADC has been shown to be predictive of favorable response $(75,76)$. While the results from these studies with small patient sample size support the value of diffusion MRI in differentiating pseudoprogression from progressive/recurrent tumor, there are several limitations that need to be considered when including this technique as part of diagnostic algorithm. First, variations in MRI
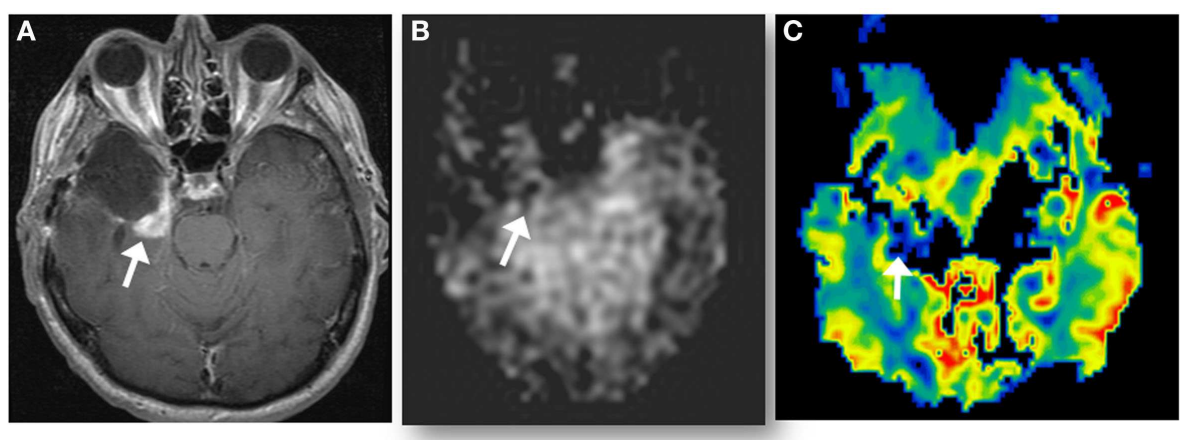

FIGURE 4 | A new enhancing lesion appeared along medial margin of right temporal resection cavity 2 months following completion of chemoradiation (A), without evidence of neither elevated CBF on ASL perfusion (B), nor elevated rCBV (C) on DSC-MRI. The lesion was confirmed as pseudoprogression on subsequent imaging. 
equipment and acquisition parameters can result in differences in calculated ADC values, and even ratio values using normal appearing brain as a reference can produce inconsistent results. This could be one reason for a lack of consistent threshold values allowing for differentiating tumor progression from necrosis. Second, ADC values within a single tumor are often heterogeneous, likely reflecting a mixture of viable and necrotic tumor tissue as mentioned earlier. Thus, ADC analyses using mean or median in tumor volume of interest may not be sensitive to spatial heterogeneity, resulting in inaccurate diagnosis of tumor progression. Histogram-based

Table 3 | Summary of MR perfusion imaging techniques.

\begin{tabular}{lll}
\hline $\begin{array}{l}\text { Perfusion } \\
\text { technique }\end{array}$ & Advantages & Disadvantages \\
\hline $\begin{array}{l}\text { Dynamic } \\
\text { susceptibility } \\
\text { contrast (DSC) }\end{array}$ & $\begin{array}{l}\text { Short imaging time } \\
\text { More widely available }\end{array}$ & $\begin{array}{l}\text { Prone to artifacts from } \\
\text { bone, metal and air }\end{array}$ \\
& & Lower spatial resolution \\
Dynamic contrast & Higher spatial resolution & Longer imaging time \\
enhanced (DCE) & Estimate vascular & Require pharmacokinetic \\
& permeability & modeling \\
Arterial spin label & Quantifies blood flow & Longer imaging time \\
(ASL) & Does not need contrast & Lower signal-to-noise ratio
\end{tabular}

methods have been developed to characterize relative mixtures of ADC values and tested as predictors of patient outcome (77, 78). While promising, implementation of this approach in routine practice remains challenging due to a requirement for tumor volume segmentation but can be facilitated with automated or semi-automated volume segmentation techniques.

\section{Magnetic resonance spectroscopy}

Magnetic resonance spectroscopy (MRS) can non-invasively measure concentrations of tissue metabolites and has shown promising applications in evaluating brain tumors including their diagnosis, grading, pre-therapy planning, and post-therapy assessment (79). MRS data can be acquired using single-voxel technique by manually defining regions-of-interest within brain lesions, and altered levels of several known metabolites including $\mathrm{N}$-acetyl aspartate (NAA), choline, creatine, and lactate provide a basis for distinguishing suspected progressive/recurrent tumor from treatment-related changes (80-83). While higher choline to creatine and choline to NAA ratios were observed in tumor progression compared to normal appearing brain or treatment necrosis, classification of tissues containing mixtures of tumor and necrosis using single-voxel techniques can be challenging. A multi-voxel acquisition approach (chemical shift imaging) can account for spatial heterogeneity in tissues and appears to improve diagnostic accuracy for detecting tumor (84-89). A recent meta-analysis reported that the diagnostic performance in differentiating glioma

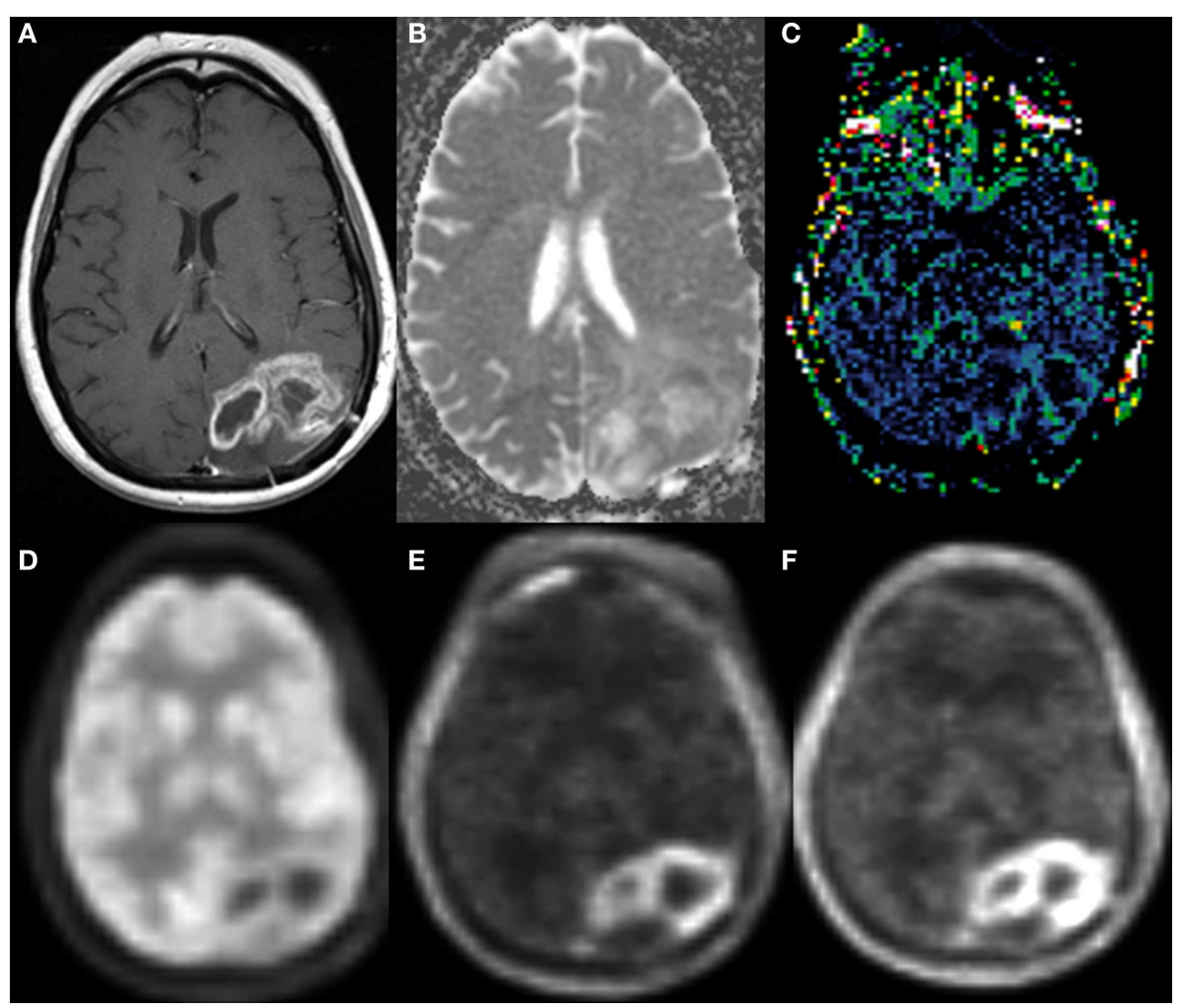

FIGURE 5 | Enlarging left parieto-occipital lobe enhancement 4 months following chemoradiation therapy (A). The enhancing region demonstrated low ADC (B) on DWI, mildly elevated rCBV (C) on DSC-MRI. FDG-PET (D) of the same lesion had less conspicuous lesion to background uptake compared to FLT-PET (E) and FET-PET (F). Subsequent resection confirmed progressive/recurrent glioblastoma. 
progression from radiation necrosis using choline to NAA ratio has sensitivity and specificity of 0.88 and 0.86 , respectively (90). In addition, biochemical changes during post-treatment necrosis appear to have temporal variability, including decreased NAA concentrations over time and a transient increase in choline following radiation therapy $(80,82,86,91,92)$, suggesting that a longitudinal evaluation using MRS may provide greater specificity.

While the diagnostic value of MRS in distinguishing progressive/recurrent tumor from treatment-induced necrosis remains to be validated, a number of challenges need to be addressed. First, MRS acquisitions using either single- or multi-voxel methods require manual input for selecting region-of-interest and placement of saturation bands, thereby introducing variability dependent on user experiences. The relative lower spatial resolution of MRS compared to conventional imaging sequences can introduce uncertainty during spectral acquisitions due to inclusion of non-lesional tissues, such as normal brain, surgical cavity, or subarachnoid spaces, requiring expert review of conventional sequences when interpreting MRS findings. Finally, MR equipment, pulse sequences, parameters, and data post-processing methods can also affect measurement reproducibility across treatment sites. These technical challenges are important to overcome for standardization and implementation of this promising technique.

\section{Positron emission tomography}

Compared to normal brain tissues, tumors often carry greater metabolic activity, which can be detected by PET imaging as increased uptake of $18 F$-fluorodeoxyglucose ( $18 F$-FDG), a radiolabeled glucose analog (93). For primary brain neoplasms, the degree of $18 F$-FDG uptake on PET has been correlated with both tumor grade $(94,95)$ and patient survival (96-102).

$18 F$-Fluorodeoxyglucose PET has also become a valuable tool for assessing treatment response in a number of human cancers (103). Several previous studies have examined the utility of FDG-PET in distinguishing radiation necrosis from tumor following radiation treatment, with a broad range of sensitivities and specificities reported (104-108). However, most of the patients included in these studies developed lesions with new or increased enhancement on MRI more than 3 months after therapy, while the majority of patients with pseudoprogression experience imaging findings within the first 3 months after chemoradiation. Thus, the results from the application of FDG-PET imaging techniques in delayed post-radiation necrosis and tumor progression may not be directly translated to its ability to distinguish between the subacute post-radiation changes (i.e., pseudoprogression) and true tumor progression. Furthermore, the use of FDG-PET in assessment of tumor progression is limited by a number of factors. First, due to the relative intrinsic high metabolism in normal brain cortex, measurement of FDG uptake within lesions near gray matter can be difficult. While delayed phase FDG-PET imaging may improve discrimination between glioma and normal gray matter, evidence supporting its use remains preliminary $(109,110)$. Second, the sensitivity of FDG-PET in determining tumor progression can be limited by the intrinsic changes of recurrent tumor affecting FDG-PET uptake; while high-grade gliomas tend to be hypermetabolic on FDG-PET (111), the level of FDG uptake of progressive/recurrent tumor may differ from that of the original tumor. Third, radiation necrosis may be associated with inflammatory processes and increased glucose metabolism (112), making elevation of FDG uptake less specific in this setting. Finally, the resolution of PET imaging is currently limited to $5 \mathrm{~mm}$. While coregistration with $\mathrm{CT}$ and $\mathrm{PET}$ on dedicated scanners can improve accuracy of lesion localization, detection and assessment of small lesions in the setting of early recurrence remains difficult. Despite these limitations, FDG-PET imaging has become widely available in major cancer centers, making this an important diagnostic tool for detecting tumor recurrence when combined with advanced MR imaging.

\section{Amino acid PET}

The short-coming of the relatively low tumor-to-background FDG uptake prompts investigations of other tumor-sensitive radiotracers with intrinsically low accumulation by normal brain tissues. In malignant brain tumors, higher proliferative activities in neoplastic cells result in increased amino acid transport (113-116), providing a basis for using radio-labeled amino acids as target for brain tumor in PET imaging. Due to relative slow uptake of amino acid in normal brain, amino acid radiotracer has the important advantage of high lesion-to-background uptake for imaging of brain tumors (Figure 5).

L-Methyl-11C-methionine (11C-MET) is the most widely characterized amino acid radiotracer in imaging of brain tumors (117-120). Compared to FDG, 11C-MET PET is superior in detecting tumor progression $(121,122)$, even in cases where there is normal or low FDG uptake by tumors (123). Other C11 based radiotracers also have shown similar promising results, including L-1-[11C]-tyrosine (11C-TYR) (124-126). However, due to the relatively short half-life of $11 \mathrm{C}$, clinical application of $11 C$ MET and $11 C$-TYR require on-site cyclotrons and their current availability remains quite limited.

Amino tracers with longer half-life radiolabel include 3'-fluoro-3'-deoxy-L-thymidine (18F-FLT) (127-130), O-2-18 F-fluoroethyl-L-tyrosine (18F-FET) (131-135), and 3,4-dihydroxy6-[18F]-fluoro-L-phenylalanine (18F-FDOPA) (136-141). These tracers all share the same features of lower normal cortical tracer uptake and facilitate clinical implementation due to the longer half-life of F18. Furthermore, kinetic modeling of radiotracer uptake may provide additional specific markers that can distinguish between tracer uptake due to BBB leakage, such as the case of radiation necrosis, and tracer accumulation due to increased active transport in growing tumors $(129,130)$. While preliminary results identify these radiotracers as early markers of treatment response and survival, (141-144), their roles in distinguishing treatmentrelated changes from true progressive/recurrent tumor remain to be validated in larger prospective trials.

\section{Antiangiogenic therapy and pseudoresponse}

Direct correlation of enhancing disease burden with glioma progression is particularly challenging in the context of antiangiogenic therapies targeting vascular endothelial factor (VEGF), such as bevacizumab, a recombinant humanized monoclonal antibody to VEGF-A, or the VEGF receptor such as cediranib, a pan-VEGF receptor tyrosine kinase inhibitor $(6,145)$. Through 
normalization of leaky tumor blood vessels, these agents can cause reduction in enhancement within 1-2 days after administration, with a radiographic response in $25-60 \%$ of patients (146). This impressive radiographic response unfortunately does not translate into increased survival. It is thought that this rapid radiographic response represents a direct action on blood vessel permeability rather than a true anti-tumor effect; a phenomenon termed "pseudoresponse" $(6,147)$. The RANO criteria address this issue by requiring a radiographic response to persist for more than 4 weeks in order to be considered a true response $(6,147)$. A further confounder in radiographic assessment of response is the tendency for antiangiogenic agents to promote progression of non-enhancing disease by selecting for an invasive tumor phenotype capable of co-opting existing blood vessels and no longer relying on angiogenesis $(6,147)$. T2-weighted or FLAIR images best represent infiltrative disease. The radiographic appearance of infiltrative tumor is often subtle and diverse, including evidence of mass effect and invasion of the cortical ribbon. Given the radiographic variability of non-enhancing infiltrative disease, the RANO group concluded current technologies fell short of providing objective measures of infiltrative tumor progression (6). Since progression of infiltrative tumor often causes clinical deterioration, the RANO criteria include the patient's clinical status in assessment of progressive non-enhancing tumor (6). Clearly, this is a suboptimal imaging surrogate and highlights the acute need for superior technologies in assessment of non-enhancing tumor progression. Here, we review promising advanced imaging modalities for the assessment of tumor burden in the context of antiangiogenic therapy.

\section{DETECTING TUMOR IN ANTIANGIOGENIC THERAPY T1 subtraction map}

Due to their effect on vascular permeability, antiangiogenic agents result in a dramatic reduction in contrast enhancement within tumor on T1-weighted images soon after initiation of therapy that is unrelated to anti-tumor effect. While the relative reduction in enhancement can be interpreted as non-enhancement by visual analyses, quantitative methods using voxel-to-voxel image subtraction between T1-weighted images before and after contrast administration may detect subtle residual enhancement and therefore provide a more accurate and reproducible assessment of true tumor extent in the context of antiangiogenic treatment $(148,149)$. Recently, Ellingson et al. analyzed 160 patients from the phase II randomized clinical trial (AVF3708g, BRAIN trial) in patients with glioblastoma treated with bevacizumab or bevacizumab and irinotecan using a T1 subtraction method (150). There was significantly improved visualization and quantification of tumor volume in post-treatment patients and calculated brain volume from subtracted images correlated with both PFS and OS better than those from un-subtracted post-contrast images. This method can be readily incorporated into clinical practice since pre and post-contrast T1-weighted imaging are usually part of standard protocol in brain tumor imaging, although ease-ofuse post-processing software for co-registration, normalization, and subtraction are necessary. Additional technical challenges also include the need of standardizing image acquisition to minimize inter-subject and intra-subject variability.

\section{T2 mapping}

While evaluation of T2/FLAIR disease in the setting of antiangiogenic therapy has been incorporated into the RANO criteria and increasingly adopted in recent clinical trials, the assessment is based on qualitative inspection without any objective guidelines. This is in part due to difficulties measuring T2/FLAIR disease with consistency and the lack of specificity for tumor tissues versus other cause of T2/FLAIR signal abnormality including edema, necrosis, and gliosis. T2 mapping is an imaging technique that quantifies $\mathrm{T} 2$ relaxation for each voxel using the effective echo times from two echoes acquired during a fastspin echo preparation. Using this method, Ellingson et al. was able to perform direct voxel-to-voxel subtraction of quantitative maps before and after bevacizumab treatment in patients with glioblastoma (151). The resulting maps allowed visualization and quantification of voxel-wise T2 changes resulting from anti-VEGF therapy (Figure 6). There was a significant decrease in $\mathrm{T} 2$ relaxation time within pre-treatment T2 abnormal regions following treatment, and an elevated residual, post-treatment; in addition, median T2 was predictive of both PFS and OS. Hattingen et al. extended the application of this technique to generate longitudinal differential T2 maps using the first post-treatment T2 map as a reference, and demonstrated non-enhancing tumor progression more clearly than conventional T2-weighted imaging (152). While the utility of T2 mapping techniques needs to be validated with further studies, this technique is promising both as an early post-treatment predictor and as a more sensitive marker of non-enhancing tumor progression in antiangiogenic therapy.

\section{Diffusion MRI in antiangiogenic therapy}

Unlike contrast-enhanced T1-weighted imaging, diffusion imaging based on ADC analyses is relatively unaffected by alterations in vascular permeability during antiangiogenic therapy (153). This advantage makes it a potentially more accurate technique in assessing the extent of tumor in this treatment setting.

A number of studies have evaluated the predictive value of pre-treatment $\mathrm{ADC}$ values for both treatment response and survival outcome. Due to heterogeneity of ADC values within tumor regions, whole-tumor histogram analyses have been increasingly utilized for evaluating the effect of different ADC subcomponents that have different prognostic or predictive values. Pope et al. applied histogram analyses of ADC values within contrast-enhancing progressive/recurrent glioblastoma before bevacizumab treatment and demonstrated that the mean value of the lower component of a two-Gaussian histogram fitting is a predictor of PFS (154). This result was subsequently validated using imaging data from a multicenter trial of patients with progressive/recurrent glioblastoma treated with bevacizumab with or without irinotecan, and the pre-treatment lower ADC component of enhancing regions was associated with OS (155). The pre-treatment ADC histogram of non-enhancing T2/FLAIR in 91 patients with progressive/recurrent glioblastoma also has been characterized using a four-component fitting model, and the resultant low to middle peak ratio was shown to be a predictor of OS independent of both the extent of the enhancing region and tumor size (156). 


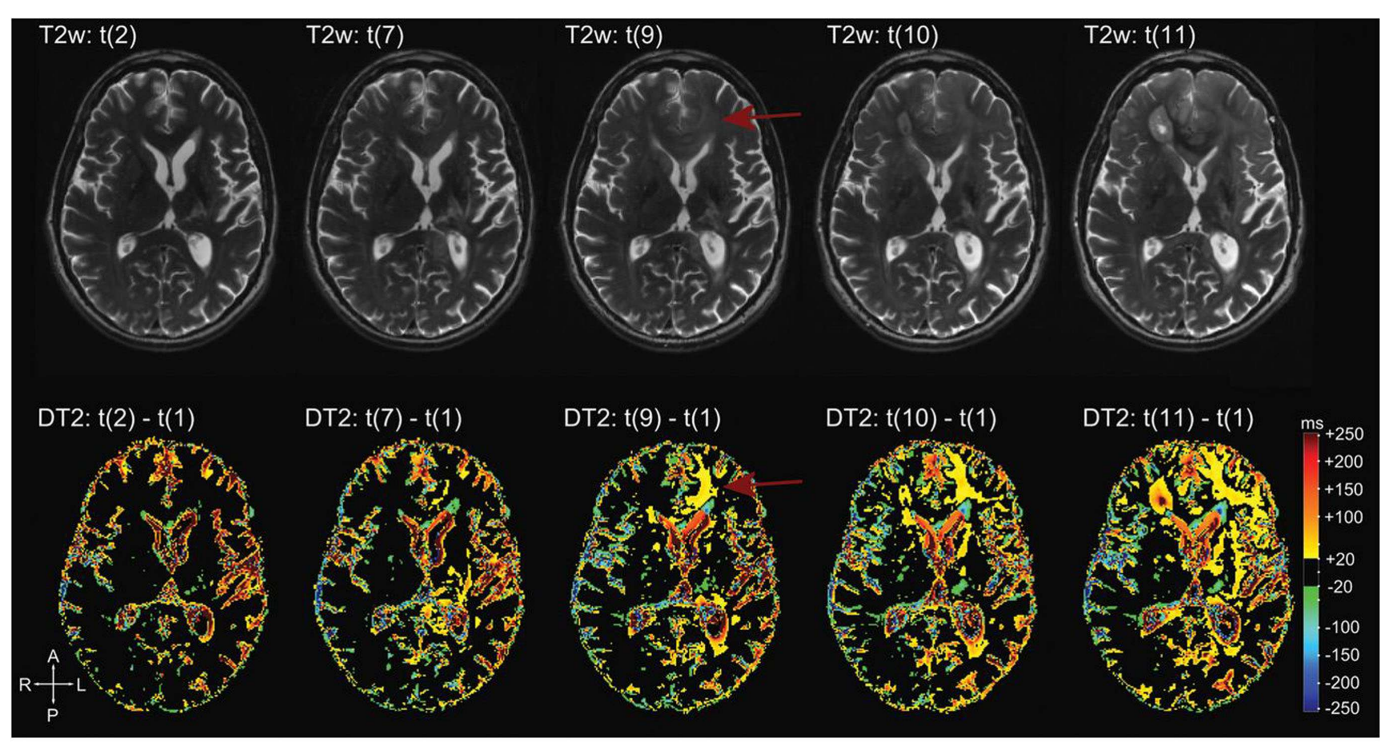

FIGURE 6 | Differential quantitative T2 maps. Reprinted with permission from Ref. (151), License Number 3520001314812 . More apparent changes on the differential T2 map (bottom row) in the left frontal lobe (arrows) compared to T2-weighted images (top row). These changes are hardly visible on conventional T2-weighted images (arrows).

Treatment-induced changes in ADC obtained by comparing pre- and early post-treatment measurements have also been tested as an imaging marker of treatment outcome. Nowosielski et al. examined the skewness, or degree of asymmetry, of ADC histograms in patients with progressive/recurrent glioblastoma and showed that patients with increasing skewness $(n=11)$ following bevacizumab/irinotecan therapy had significantly shorter PFS than did patients with decreasing or stable skewness (157). While histogram-based approaches can analyze the relative proportion of individual ADC subtypes, regional changes before and after therapy cannot be captured. Using functional diffusion map (fDM) methods by voxel-wise subtraction of pre- and post-treatment ADC maps, precise magnitude of change in ADC at all tumor locations can be studied. Ellingson et al. $(158,159)$ applied a graded fDM using multiple thresholds of ADC change to assess antiangiogenic therapy in progressive/recurrent glioblastoma and showed that the volume of decreased ADC values between 0.25 and $0.40 \mu \mathrm{m}^{2} / \mathrm{ms}$ in both enhancing and non-enhancing regions is associated with OS.

Change in ADC can also be followed longitudinally by serial MRI. Using percentage change of low ADC volume over time, Gerstner demonstrated progressive increase of percent volume with low ADC volume within non-enhancing regions following cediranib therapy to correlate with infiltrative tumor progression (160). Similarly, Jain et al. compared mean ADC within contrast-enhancing and non-enhancing volumes and determined that patients with PD showed a sequential increase in the negative percent change of $\mathrm{ADC}$ values following bevacizumab therapy (161). While ADC values can correlate with tumor growth in serial imaging, developing automated methods of voxel-wise subtraction is important for real-time adoption of this method for use in prospective clinical trials.

\section{High b-value MR diffusion imaging}

In most commonly used clinical MR scanners, the $b$ value of diffusion gradient is usually $1000 \mathrm{~s} / \mathrm{mm}^{2}$. When the $b$ value increases to beyond $3000 \mathrm{~s} / \mathrm{mm}^{2}$, diffusion signal decay is no longer monoexponential, and analysis of higher range $b$ values potentially can result in greater imaging contrast between different tissue types. Applying high $b$-value diffusion imaging to characterize brain tumors, Seo et al. demonstrated that the degree of ADC decrease was greater in tumors compared with normal brain tissue (162). Using histogram analysis of ADC maps based on entire tumor volume, Kang et al. demonstrated that the histogram parameters derived from high $b$ values performed better diagnostically than those from standard $b$ values in differentiating high- from low-grade gliomas. ADC values decreased when the $b$ value was increased from 1000 to $3000 \mathrm{~s} / \mathrm{mm}^{2}$, and a greater decrease was observed with higher tumor grades (163). In 4 of 10 patients with progressive/recurrent glioma treated with bevacizumab, high $b$ value diffusion imaging identified pseudoresponse at earlier times compared to both the Macdonald and RANO criteria (164).

\section{MR perfusion imaging}

The ability of perfusion imaging techniques to measure blood flow dynamics in vivo makes them potentially useful tools not only for understanding the effect and mechanism of antiangiogenic therapy, but also for providing prognostic or predictive information important for patient selection and treatment decisions. While mechanisms of action of antiangiogenic agents are not fully understood, early decrease in Ktrans, an DCE-MR marker of vascular permeability (49), can be detected at day 1 after a single dose of cediranib in patients with progressive/recurrent glioblastoma, and the decrease has been shown to be associated with improved PFS and OS $(146,165)$. The improved blood flow 
was also associated with tumor oxygenation (166). These observations support the theory of "vascular normalization" as the mechanism of action (167), and a "vascular normalization index" (VNI) combining Ktrans and circulating collagen IV were subsequently proposed as a marker to predict survival (165). A similar VNI parameter can be obtained by comparing pre-treatment and 1-day post-treatment DSC-MRI using a single double-echo acquisition. This new VNI parameter combining changes in tumor CBV and an apparent transfer constant (Ka) using a leakage correction method was predictive of PFS and OS in 30 patients with progressive/recurrent glioblastomas enrolled in a phase II clinical trial of an oral pan-VEGF receptor tyrosine kinase inhibitor (45).

Using DSC-MRI, Essock-Burns examined 35 patients with newly diagnosed GBM who received temozolomide chemoradiotherapy with enzastaurin, an oral PKC isoform kinase inhibitor, after surgical resection (168). Responders at 6 months showed an increased percent recovery (PR) between baseline and 2 months into therapy, indicating improved permeability, whereas nonresponders at 6 months showed significantly increased peak height (PH), a marker of microvascular density similar to CBV (169) between baseline and 1 month. Using standardized rCBV, a consistent intensity scale regardless of MR scanner model or field strength, Schmainda et al. examined the prognostic values of DSCMRI findings in 36 patients with progressive/recurrent high-grade glioma 60 days before and 20-60 days after starting bevacizumab and reported longer OS if pre- or post-treatment standardized rCBV is less than 4400 (170). The use of standardized perfusion parameters can reduce variability when comparing findings from different subjects, scanners, or using different acquisition techniques, but the reported threshold values require validation in larger clinical data sets.

\section{Evaluating treatment response to immunotherapy}

A newer challenge is the differentiation of pseudoprogression from true progression in patients who receive immunotherapy. The FDA approval of two recent immunotherapy approaches, Sipuleucel-T (APC8015) for prostate cancer and ipilimumab for melanoma, as well as ongoing trials showing efficacy of immunotherapy against challenging cancers, heralds a new era of cancer treatment $(171,172)$. Ongoing immunotherapy trials in glioblastoma hold great promise for improved outcomes in this devastating illness $(171,172)$. Since the goal of immunotherapy is to harness the patient's immune system to fight cancer, inflammation in the tumor bed is expected much more than with cytotoxic chemotherapies. Experience in melanoma trials has shown that while tumor regression is often low (only $10 \%$ of patients), many patients can have prolonged periods of stability (173). This would potentially go undetected using RR as an endpoint (173-175). In addition, some tumors may develop new lesions or transiently increased size before eventually becoming smaller. To re-define response in the context of immunotherapy, assess efficacy of treatment in clinical trials, prevent patients from discontinuing a potentially beneficial treatment, as well as to ensure that patients do not remain on a potentially harmful, ineffective treatment, Wolchuk
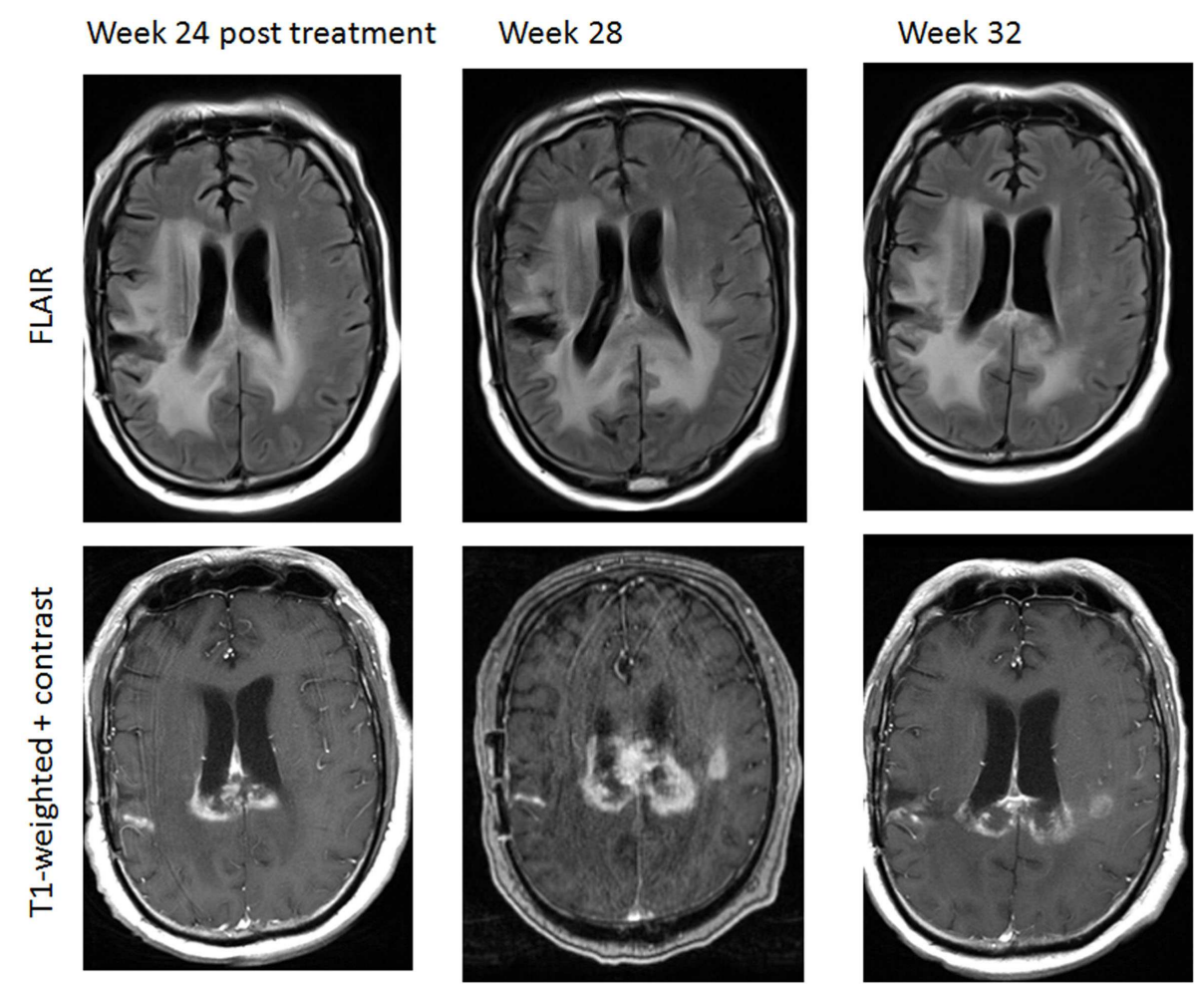

FIGURE 7 | A patient with progressive glioblastoma treated by immunotherapy including nivolumab (anti-PD1antibody) and ipilimumab (anti-CTLA-4 antibody). There was a transient increase in enhancing area in the posterior corpus callosum and left corona radiation 24 weeks following therapy initiation, consistent with pseudoprogression. Week 32 imaging was obtained after 1 week of corticosteroid therapy. 
et al. proposed a new set of response criteria termed immunerelated response criteria (irRC) for melanoma (173). The irRC allow for patients tolerating therapy to stay on treatment beyond initial progression for another 4 weeks and define disease progression as an increase in the measurement of overall tumor burden rather than the appearance of new lesions $(173,176)$.

Ongoing immunotherapy trials for glioblastoma also show complex radiographic effects, including inflammation leading to the enlargement of pre-existing enhancing lesions or the appearance of new enhancing lesions (Figure 7). It is particularly challenging given current technologies to differentiate pseudoprogression caused by an anti-tumor mediated immune response from true progression using the RANO criteria, as timing of immune-mediated anti-tumor effects seems to differ from that seen with cytotoxic chemotherapies $(173,177,178)$. The mechanism of contrast enhancement during pseudoprogression following immunotherapy is presently unclear and may be different from that following traditional chemoradiation therapy. Current efforts are ongoing to incorporate immune-related considerations into the RANO criteria (iRANO) to allow for improved response assessment and provide clinical guidelines for patients undergoing immunotherapy trials for glioblastoma. The iRANO criteria will define PD as persisting beyond a determined period of time after initial radiographic evidence of progression, allowing for patients with no significant neurological decline to stay on a potentially efficacious treatment longer and also allow for discontinuation of treatment earlier in the context of significant neurological decline. While iRANO criteria are currently being developed, advanced neuroimaging modalities useful in differentiating pseudoprogression from true progression may become invaluable in making clinical decisions in this rapidly evolving field of immunotherapy.

To date, only a few studies have evaluated advanced imaging techniques in characterizing pseudoprogression following immunotherapy. Vrabec et al. retrospectively assessed MR perfusion and diffusion imaging findings of eight patients with progressive/recurrent glioblastoma following dendritic cell immune therapy. In this small series, contrast-enhancing areas secondary to immune therapy-induced inflammation showed significant differences in maximum rCBV ratios and minimum ADC values compared to progressive/recurrent tumor (179). With a growing number of immunotherapy-based clinical trials for malignant glioma, the clinical and imaging characteristics of pseudoprogression with respect to each type of immunotherapy ultimately will become better understood. Most importantly, there is an urgent need to explore, validate, and standardize radiographic criteria based on both available and new imaging techniques for patients receiving immunotherapy in order to better define treatment efficacy.

\section{CONCLUSION}

The updated criteria proposed by the RANO group have incorporated new guidelines to address the phenomena of pseudoprogression and pseudoresponse in patients with high-grade glioma. A minimum standard protocol necessary for evaluating radiographic response per RANO criteria should consist of preand post-contrast T1-weighted sequence as well as T2 and/or FLAIR sequences, ideally with the same magnetic field strength, acquisition parameters, and contrast dose throughout baseline and subsequent follow-up MRI studies to improve measurement reproducibility. The time interval between MRI studies immediately following radiation treatment is typically 1 month unless new clinical symptoms mandate earlier imaging. Advanced MRI sequences, such as perfusion and diffusion-weighted imaging, are also recommended as part of a standard imaging protocol to be readily evaluated in conjunction with conventional sequences when tumor progression or post-treatment changes are suspected. Other imaging techniques, such as MRS and PET, may help evaluate suspected lesion(s) and may require referral to centers with expertise in neuroimaging as well as neuro-oncology care.

With a growing number of new therapeutic options available for glioblastoma patients, diagnostic imaging tools allowing accurate characterizations of tumor response or resistance are urgently needed. We reviewed a number of advanced imaging methods for evaluating pseudoprogression following standard chemoradiation therapy and clinical trials including immunotherapy, as well as pseudoresponse in the setting of antiangiogenic therapy. As these techniques are increasingly incorporated into routine brain tumor imaging protocols, the sensitivity and specificity for detecting true tumor growth or shrinkage will be better defined. These advances should come with an emphasis on standardization and ease of implementation, which are required for subsequent validation and clinical use.

\section{ACKNOWLEDGMENTS}

We thank Rafael Rojas MD, Beth Isreal Medical Center, Boston, MA, USA, Laura Horky, MD, Park, Mi-Ae, PhD, Brigham and Women's Hospital, Boston, MA, USA, for providing the figures.

\section{REFERENCES}

1. Stupp R, Hegi ME, Mason WP, van den Bent MJ, Taphoorn MJB, Janzer $\mathrm{RC}$, et al. Effects of radiotherapy with concomitant and adjuvant temozolomide versus radiotherapy alone on survival in glioblastoma in a randomised phase III study: 5-year analysis of the EORTC-NCIC trial. Lancet Oncol (2009) 10:459-66. doi:10.1016/S1470-2045(09)70025-7

2. Ostrom QT, Gittleman H, Liao P, Rouse C, Chen Y, Dowling J, et al. CBTRUS statistical report: primary brain and central nervous system tumors diagnosed in the United States in 2007-2011. Neuro Oncol (2014) 16(Suppl 4):iv1-63. doi:10.1093/neuonc/nou223

3. Brennan CW, Verhaak RGW, McKenna A, Campos B, Noushmehr H, Salama SR, et al. The somatic genomic landscape of glioblastoma. Cell (2013) 155:462-77. doi:10.1016/j.cell.2013.09.034

4. Wen PY, Kesari S. Malignant gliomas in adults. N Engl J Med (2008) 359:492-507. doi:10.1056/NEJMra0708126

5. Stupp R, Mason WP, van den Bent MJ, Weller M, Fisher B, Taphoorn MJB, et al. Radiotherapy plus concomitant and adjuvant temozolomide for glioblastoma. N Engl J Med (2005) 352:987-96. doi:10.1056/NEJMoa043330

6. Wen PY, Macdonald DR, Reardon DA, Cloughesy TF, Sorensen AG, Galanis E, et al. Updated response assessment criteria for high-grade gliomas: response assessment in neuro-oncology working group. J Clin Oncol (2010) 28:1963-72. doi:10.1200/JCO.2009.26.3541

7. Taal W, Oosterkamp HM, Walenkamp AME, Dubbink HJ, Beerepoot LV, Hanse MCJ, et al. Single-agent bevacizumab or lomustine versus a combination of bevacizumab plus lomustine in patients with recurrent glioblastoma (BELOB trial): a randomised controlled phase 2 trial. Lancet Oncol (2014) 15:943-53. doi:10.1016/S1470-2045(14)70314-6

8. Hottinger AF, Stupp R, Homicsko K. Standards of care and novel approaches in the management of glioblastoma multiforme. Chin J Cancer (2014) 33:32-9. doi: $10.5732 /$ cjc. 013.10207

9. Wen PY, Ellingson BM, Reardon DA, Fine HA, Abrey L, Ballman K, et al. Report of the jumpstarting brain tumor drug development 5 coalition and FDA clinical 
trials neuroimaging endpoint workshop (January 30, 2014, Bethesda MD). Neuro Oncol (2014) 16:vii36-47. doi:10.1093/neuonc/nou226

10. Lamborn KR, Yung WKA, Chang SM, Wen PY, Cloughesy TF, DeAngelis LM, et al. Progression-free survival: an important end point in evaluating therapy for recurrent high-grade gliomas. Neuro Oncol (2008) 10:162-70. doi:10.1215/15228517-2007-062

11. Niendorf HP, Laniado M, Semmler W, Schörner W, Felix R. Dose administration of gadolinium-DTPA in MR imaging of intracranial tumors. AJNR Am J Neuroradiol (1987) 8:803-15.

12. Macdonald DR, Cascino TL, Schold SC Jr, Cairncross JG. Response criteria for phase II studies of supratentorial malignant glioma. J Clin Oncol (1990) 8:1277-80.

13. Therasse P, Arbuck SG, Eisenhauer EA, Wanders J, Kaplan RS, Rubinstein L, et al. New guidelines to evaluate the response to treatment in solid tumors. European Organization for Research and Treatment of Cancer, National Cancer Institute of the United States, National Cancer Institute of Canada. J Natl Cancer Inst (2000) 92:205-16. doi:10.1093/jnci/92.3.205

14. Van den Bent MJ, Vogelbaum MA, Wen PY, Macdonald DR, Chang SM. End point assessment in gliomas: novel treatments limit usefulness of classical Macdonald's criteria. J Clin Oncol (2009) 27:2905-8. doi:10.1200/JCO.2009. 22.4998

15. Brandsma D, Stalpers L, Taal W, Sminia P, van den Bent MJ. Clinical features, mechanisms, and management of pseudoprogression in malignant gliomas. Lancet Oncol (2008) 9:453-61. doi:10.1016/S1470-2045(08)70125-6

16. Valtonen S, Timonen U, Toivanen P, Kalimo H, Kivipelto L, Heiskanen O, et al. Interstitial chemotherapy with carmustine-loaded polymers for highgrade gliomas: a randomized double-blind study. Neurosurgery (1997) 41:44-8. doi:10.1097/00006123-199707000-00011

17. Westphal M, Hilt DC, Bortey E, Delavault P, Olivares R, Warnke PC, et al. A phase 3 trial of local chemotherapy with biodegradable carmustine (BCNU) wafers (Gliadel wafers) in patients with primary malignant glioma. Neuro Oncol (2003) 5:79-88. doi:10.1215/S1522-8517-02-00023-6

18. Westphal M, Ram Z, Riddle V, Hilt D, Bortey E. Executive committee of the Gliadel Study Group. Gliadel wafer in initial surgery for malignant glioma: long-term follow-up of a multicenter controlled trial. Acta Neurochir (Wien) (2006) 148:269-75. doi:10.1007/s00701-005-0707-z

19. Brem H, Piantadosi S, Burger PC, Walker M, Selker R, Vick NA, et al. Placebo-controlled trial of safety and efficacy of intraoperative controlled delivery by biodegradable polymers of chemotherapy for recurrent gliomas. The Polymer-brain Tumor Treatment Group. Lancet (1995) 345:1008-12. doi:10.1016/S0140-6736(95)90755-6

20. Subach BR, Witham TF, Kondziolka D, Lunsford LD, Bozik M, Schiff D. Morbidity and survival after 1,3-bis(2-chloroethyl)-1-nitrosourea wafer implantation for recurrent glioblastoma: a retrospective case-matched cohort series. Neurosurgery (1999) 45:17-22. doi:10.1097/00006123-199907000-00004

21. Della Puppa A, Rossetto M, Ciccarino P, Del Moro G, Rotilio A, Manara R, et al. The first 3 months after BCNU wafers implantation in high-grade glioma patients: clinical and radiological considerations on a clinical series. Acta Neurochir (Wien) (2010) 152:1923-31. doi:10.1007/s00701-010-0759-6

22. Ulmer S, Spalek K, Nabavi A, Schultka S, Mehdorn HM, Kesari S, et al. Temporal changes in magnetic resonance imaging characteristics of Gliadel wafers and of the adjacent brain parenchyma. Neuro Oncol (2012) 14:482-90. doi:10.1093/neuonc/nos003

23. Colen RR, Zinn PO, Hazany S, Do-Dai D, Wu JK, Yao K, et al. Magnetic resonance imaging appearance and changes on intracavitary Gliadel wafer placement: a pilot study. World J Radiol (2011) 3:266-72. doi:10.4329/wjr.v3.i11.266

24. Rosen BR, Belliveau JW, Vevea JM, Brady TJ. Perfusion imaging with NMR contrast agents. Magn Reson Med (1990) 14:249-65. doi:10.1002/mrm.1910140211

25. Villringer A, Rosen BR, Belliveau JW, Ackerman JL, Lauffer RB, Buxton RB, et al. Dynamic imaging with lanthanide chelates in normal brain: contrast due to magnetic susceptibility effects. Magn Reson Med (1988) 6:164-74. doi:10.1002/mrm.1910060205

26. Rosen BR, Belliveau JW, Buchbinder BR, McKinstry RC, Porkka LM, Kennedy $\mathrm{DN}$, et al. Contrast agents and cerebral hemodynamics. Magn Reson Med (1991) 19:285-92. doi:10.1002/mrm.1910190216

27. Emblem KE, Bjornerud A. An automatic procedure for normalization of cerebral blood volume maps in dynamic susceptibility contrast-based glioma imaging. AJNR Am J Neuroradiol (2009) 30:1929-32. doi:10.3174/ajnr.A1680
28. Bedekar D, Jensen T, Schmainda KM. Standardization of relative cerebral blood volume (rCBV) image maps for ease of both inter- and intrapatient comparisons. Magn Reson Med (2010) 64:907-13. doi:10.1002/mrm.22445

29. Jain R, Scarpace L, Ellika S, Schultz LR, Rock JP, Rosenblum ML, et al. First-pass perfusion computed tomography: initial experience in differentiating recurrent brain tumors from radiation effects and radiation necrosis. Neurosurgery (2007) 61:778-86. doi:10.1227/01.NEU.0000298906.48388.26

30. Barajas RF, Chang JS, Segal MR, Parsa AT, McDermott MW, Berger MS, et al. Differentiation of recurrent glioblastoma multiforme from radiation necrosis after external beam radiation therapy with dynamic susceptibility-weighted contrast-enhanced perfusion MR imaging. Radiology (2009) 253:486-96. doi:10.1148/radiol.2532090007

31. Hu LS, Baxter LC, Smith KA, Feuerstein BG, Karis JP, Eschbacher JM, et al. Relative cerebral blood volume values to differentiate high-grade glioma recurrence from posttreatment radiation effect: direct correlation between imageguided tissue histopathology and localized dynamic susceptibility-weighted contrast-enhanced perfusion MR imaging measurements. AJNR Am J Neuroradiol (2009) 30:552-8. doi:10.3174/ajnr.A1377

32. Matsusue E, Fink JR, Rockhill JK, Ogawa T, Maravilla KR. Distinction between glioma progression and post-radiation change by combined physiologic MR imaging. Neuroradiology (2010) 52:297-306. doi:10.1007/s00234-009-0613-9

33. Sugahara T, Korogi Y, Tomiguchi S, Shigematsu Y, Ikushima I, Kira T, et al. Posttherapeutic intraaxial brain tumor: the value of perfusion-sensitive contrastenhanced MR imaging for differentiating tumor recurrence from nonneoplastic contrast-enhancing tissue. AJNR Am J Neuroradiol (2000) 21:901-9.

34. Baek HJ, Kim HS, Kim N, Choi YJ, Kim YJ. Percent change of perfusion skewness and kurtosis: a potential imaging biomarker for early treatment response in patients with newly diagnosed glioblastomas. Radiology (2012) 264:834-43. doi:10.1148/radiol.12112120

35. Hu LS, Eschbacher JM, Heiserman JE, Dueck AC, Shapiro WR, Liu S, et al. Reevaluating the imaging definition of tumor progression: perfusion MRI quantifies recurrent glioblastoma tumor fraction, pseudoprogression, and radiation necrosis to predict survival. Neuro Oncol (2012) 14:919-30. doi:10.1093/neuonc/nos112

36. Tsien C, Galbán CJ, Chenevert TL, Johnson TD, Hamstra DA, Sundgren PC, et al. Parametric response map as an imaging biomarker to distinguish progression from pseudoprogression in high-grade glioma. J Clin Oncol (2010) 28:2293-9. doi:10.1200/JCO.2009.25.3971

37. Cao Y, Shen Z, Chenevert TL, Ewing JR. Estimate of vascular permeability and cerebral blood volume using Gd-DTPA contrast enhancement and dynamic T2*-weighted MRI. J Magn Reson Imaging (2006) 24:288-96. doi:10.1002/ jmri.20634

38. Mangla R, Singh G, Ziegelitz D, Milano MT, Korones DN, Zhong J, et al. Changes in relative cerebral blood volume 1 month after radiationtemozolomide therapy can help predict overall survival in patients with glioblastoma. Radiology (2010) 256:575-84. doi:10.1148/radiol.10091440

39. Paulson ES, Schmainda KM. Comparison of dynamic susceptibility-weighted contrast-enhanced MR methods: recommendations for measuring relative cerebral blood volume in brain tumors. Radiology (2008) 249:601-13. doi: 10.1148/radiol.2492071659

40. Hu LS, Baxter LC, Pinnaduwage DS, Paine TL, Karis JP, Feuerstein BG, et al. Optimized preload leakage-correction methods to improve the diagnostic accuracy of dynamic susceptibility-weighted contrast-enhanced perfusion MR imaging in posttreatment gliomas. AJNR Am J Neuroradiol (2010) 31:40-8. doi:10.3174/ajnr.A1787

41. Uematsu H, Maeda M. Double-echo perfusion-weighted MR imaging: basic concepts and application in brain tumors for the assessment of tumor blood volume and vascular permeability. Eur Radiol (2006) 16:180-6. doi:10.1007/ s00330-005-2807-9

42. Boxerman JL, Schmainda KM, Weisskoff RM. Relative cerebral blood volume maps corrected for contrast agent extravasation significantly correlate with glioma tumor grade, whereas uncorrected maps do not. AJNR Am J Neuroradiol (2006) 27:859-67.

43. Kassner A, Annesley DJ, Zhu XP, Li KL, Kamaly-Asl ID, Watson Y, et al. Abnormalities of the contrast re-circulation phase in cerebral tumors demonstrated using dynamic susceptibility contrast-enhanced imaging: a possible marker of vascular tortuosity. J Magn Reson Imaging (2000) 11:103-13. doi:10.1002/(SICI)1522-2586(200002)11:2<103::AID-JMRI5>3.0.CO;2-Z 
44. Bjornerud A, Sorensen AG, Mouridsen K, Emblem KE. T1- and T2*-dominant extravasation correction in DSC-MRI: part I - theoretical considerations and implications for assessment of tumor hemodynamic properties. J Cereb Blood Flow Metab (2011) 31:2041-53. doi:10.1038/jcbfm.2011.52

45. Emblem KE, Bjornerud A, Mouridsen K, Borra RJH, Batchelor TT, Jain RK, et al. (1)- and $\mathrm{T}(2)\left(^{*}\right)$-dominant extravasation correction in DSC-MRI: part II-predicting patient outcome after a single dose of cediranib in recurrent glioblastoma patients. J Cereb Blood Flow Metab (2011) 31:2054-64. doi:10.1038/jcbfm.2011.39

46. Gahramanov S, Muldoon LL, Varallyay CG, Li X, Kraemer DF, Fu R, et al. Pseudoprogression of glioblastoma after chemo- and radiation therapy: diagnosis by using dynamic susceptibility-weighted contrast-enhanced perfusion MR imaging with ferumoxytol versus gadoteridol and correlation with survival. Radiology (2013) 266:842-52. doi:10.1148/radiol.12111472

47. Tofts PS, Kermode AG. Measurement of the blood-brain barrier permeability and leakage space using dynamic MR imaging. 1. Fundamental concepts. Magn Reson Med (1991) 17:357-67. doi:10.1002/mrm.1910170208

48. Tofts PS. Modeling tracer kinetics in dynamic Gd-DTPA MR imaging. J Magn Reson Imaging (1997) 7:91-101. doi:10.1002/jmri.1880070113

49. Tofts PS, Brix G, Buckley DL, Evelhoch JL, Henderson E, Knopp MV, et al. Estimating kinetic parameters from dynamic contrast-enhanced T(1)-weighted MRI of a diffusable tracer: standardized quantities and symbols. J Magn Reson Imaging (1999) 10:223-32. doi:10.1002/(SICI)1522-2586(199909)10:3<223: :AID-JMRI2>3.0.CO;2-S

50. Larsen VA, Simonsen HJ, Law I, Larsson HBW, Hansen AE. Evaluation of dynamic contrast-enhanced T1-weighted perfusion MRI in the differentiation of tumor recurrence from radiation necrosis. Neuroradiology (2013) 55:361-9. doi:10.1007/s00234-012-1127-4

51. Bisdas S, Naegele T, Ritz R, Dimostheni A, Pfannenberg C, Reimold M, et al. Distinguishing recurrent high-grade gliomas from radiation injury: a pilot study using dynamic contrast-enhanced MR imaging. Acad Radiol (2011) 18:575-83. doi:10.1016/j.acra.2011.01.018

52. Narang J, Jain R, Arbab AS, Mikkelsen T, Scarpace L, Rosenblum ML, et al. Differentiating treatment-induced necrosis from recurrent/progressive brain tumor using nonmodel-based semiquantitative indices derived from dynamic contrast-enhanced T1-weighted MR perfusion. Neuro Oncol (2011) 13:1037-46. doi:10.1093/neuonc/nor075

53. Kim HS, Ju Goh M, Kim N, Choi CG, Kim SJ, Kim JH. Which combination of MR imaging modalities is best for predicting recurrent glioblastoma? Study of diagnostic accuracy and reproducibility. Radiology (2014) 273(3):831-43. doi:10.1148/radiol.14132868

54. Williams DS, Detre JA, Leigh JS, Koretsky AP. Magnetic resonance imaging of perfusion using spin inversion of arterial water. Proc Natl Acad Sci US A (1992) 89:212-6. doi:10.1073/pnas.89.1.212

55. Silva AC, Kim SG, Garwood M. Imaging blood flow in brain tumors using arterial spin labeling. Magn Reson Med (2000) 44:169-73. doi:10.1002/15222594(200008)44:2<169::AID-MRM1>3.0.CO;2-U

56. Furtner J, Schöpf V, Schewzow K, Kasprian G, Weber M, Woitek R, et al. Arterial spin-labeling assessment of normalized vascular intratumoral signal intensity as a predictor of histologic grade of astrocytic neoplasms. AJNR Am J Neuroradiol (2014) 35(3):482-9. doi:10.3174/ajnr.A3705

57. Warmuth C, Gunther M, Zimmer C. Quantification of blood flow in brain tumors: comparison of arterial spin labeling and dynamic susceptibilityweighted contrast-enhanced MR imaging. Radiology (2003) 228:523-32. doi:10.1148/radiol.2282020409

58. Choi YJ, Kim HS, Jahng G-H, Kim SJ, Suh DC. Pseudoprogression in patients with glioblastoma: added value of arterial spin labeling to dynamic susceptibility contrast perfusion MR imaging. Acta Radiol (2013) 54:448-54. doi:10.1177/0284185112474916

59. Geer CP, Simonds J, Anvery A, Chen MY, Burdette JH, Zapadka ME, et al. Does MR perfusion imaging impact management decisions for patients with brain tumors? A prospective study. AJNR Am J Neuroradiol (2012) 33(3):556-62. doi:10.3174/ajnr.A2811

60. Yamasaki F, Kurisu K, Satoh K, Arita K, Sugiyama K, Ohtaki M, et al. Apparent diffusion coefficient of human brain tumors at MR imaging1. Radiology (2005) 235:985-91. doi:10.1148/radiol.2353031338

61. Guo AC, Cummings TJ, Dash RC, Provenzale JM. Lymphomas and high-grade astrocytomas: comparison of water diffusibility and histologic characteristics1. Radiology (2002) 224:177-83. doi:10.1148/radiol.2241010637
62. Dorenbeck U, Grunwald IQ, Schlaier J, Feuerbach S. Diffusion-weighted imaging with calculated apparent diffusion coefficient of enhancing extra-axial masses. J Neuroimaging (2005) 15:341-7. doi:10.1177/1051228405279991

63. Rumboldt Z, Camacho DLA, Lake D, Welsh CT, Castillo M. Apparent diffusion coefficients for differentiation of cerebellar tumors in children. AJNR Am J Neuroradiol (2006) 27:1362-9.

64. Hayashida Y, Hirai T, Morishita S, Kitajima M, Murakami R, Korogi Y, et al. Diffusion-weighted imaging of metastatic brain tumors: comparison with histologic type and tumor cellularity. AJNR Am J Neuroradiol (2006) 27:1419-25.

65. Sugahara T, Korogi Y, Kochi M, Ikushima I, Shigematu Y, Hirai T, et al. Usefulness of diffusion-weighted MRI with echo-planar technique in the evaluation of cellularity in gliomas. J Magn Reson Imaging (1999) 9:53-60. doi:10.1002/(SICI)1522-2586(199901)9:1<53::AID-JMRI7>3.0.CO;2-2

66. Murakami R, Hirai T, Sugahara T, Fukuoka H, Toya R, Nishimura S, et al. Grading astrocytic tumors by using apparent diffusion coefficient parameters: superiority of a one- versus two-parameter pilot method1. Radiology (2009) 251:838-45. doi:10.1148/radiol.2513080899

67. Higano S, Yun X, Kumabe T, Watanabe M, Mugikura S, Umetsu A, et al. Malignant astrocytic tumors: clinical importance of apparent diffusion coefficient in prediction of grade and prognosisl. Radiology (2006) 241:839-46. doi:10.1148/radiol.2413051276

68. Kitis O, Altay H, Calli C, Yunten N, Akalin T, Yurtseven T. Minimum apparent diffusion coefficients in the evaluation of brain tumors. Eur J Radiol (2005) 55:393-400. doi:10.1016/j.ejrad.2005.02.004

69. Ellingson BM, Malkin MG, Rand SD, Connelly JM, Quinsey C, LaViolette PS, et al. Validation of functional diffusion maps (fDMs) as a biomarker for human glioma cellularity. J Magn Reson Imaging (2010) 31:538-48. doi:10.1002/jmri.22068

70. Provenzale JM, McGraw P, Mhatre P, Guo AC, Delong D. Peritumoral brain regions in gliomas and meningiomas: investigation with isotropic diffusionweighted MR imaging and diffusion-tensor MR imaging1. Radiology (2004) 232:451-60. doi:10.1148/radiol.2322030959

71. Smith JS, Cha S, Mayo MC, McDermott MW, Parsa AT, Chang SM, et al. Serial diffusion-weighted magnetic resonance imaging in cases of glioma: distinguishing tumor recurrence from postresection injury. J Neurosurg (2005) 103:428-38. doi:10.3171/jns.2005.103.3.0428

72. Hein PA, Eskey CJ, Dunn JF, Hug EB. Diffusion-weighted imaging in the followup of treated high-grade gliomas: tumor recurrence versus radiation injury. AJNR Am J Neuroradiol (2004) 25:201-9.

73. Asao C, Korogi Y, Kitajima M, Hirai T, Baba Y, Makino K, et al. Diffusionweighted imaging of radiation-induced brain injury for differentiation from tumor recurrence. AJNR Am J Neuroradiol (2005) 26:1455-60.

74. Sundgren PC, Fan X, Weybright P, Welsh RC, Carlos RC, Petrou M, et al. Differentiation of recurrent brain tumor versus radiation injury using diffusion tensor imaging in patients with new contrast-enhancing lesions. Magn Reson Imaging (2006) 24:1131-42. doi:10.1016/j.mri.2006.07.008

75. Chenevert TL, Stegman LD, Taylor JM, Robertson PL, Greenberg HS, Rehemtulla A, et al. Diffusion magnetic resonance imaging: an early surrogate marker of therapeutic efficacy in brain tumors. J Natl Cancer Inst (2000) 92:2029-36. doi:10.1093/jnci/92.24.2029

76. Chenevert TL, McKeever PE, Ross BD. Monitoring early response of experimental brain tumors to therapy using diffusion magnetic resonance imaging. Clin Cancer Res (1997) 3:1457-66.

77. Ellingson BM, Cloughesy TF, Lai A, Nghiemphu PL, Liau LM, Pope WB. Quantitative probabilistic functional diffusion mapping in newly diagnosed glioblastoma treated with radiochemotherapy. Neuro Oncol (2013) 15:382-90. doi:10.1093/neuonc/nos314

78. Ellingson BM, Cloughesy TF, Zaw T, Lai A, Nghiemphu PL, Harris R, et al. Functional diffusion maps (fDMs) evaluated before and after radiochemotherapy predict progression-free and overall survival in newly diagnosed glioblastoma. Neuro Oncol (2012) 14:333-43. doi:10.1093/neuonc/nor220

79. Oz G, Alger JR, Barker PB, Bartha R, Bizzi A, Boesch C, et al. Clinical proton MR spectroscopy in central nervous system disorders. Radiology (2014) 270:658-79. doi:10.1148/radiol.13130531

80. Schlemmer HP, Bachert P, Herfarth KK, Zuna I, Debus J, van Kaick G. Proton MR spectroscopic evaluation of suspicious brain lesions after stereotactic radiotherapy. AJNR Am J Neuroradiol (2001) 22:1316-24.

81. Dowling C, Bollen AW, Noworolski SM, McDermott MW, Barbaro NM, Day $\mathrm{MR}$, et al. Preoperative proton MR spectroscopic imaging of brain tumors: 
correlation with histopathologic analysis of resection specimens. AJNR Am J Neuroradiol (2001) 22:604-12.

82. Rabinov JD, Lee PL, Barker FG, Louis DN, Harsh GR, Cosgrove GR, et al. In vivo 3-T MR spectroscopy in the distinction of recurrent glioma versus radiation effects: initial experience. Radiology (2002) 225:871-9. doi:10.1148/ radiol.2253010997

83. Prat R, Galeano I, Lucas A, Martínez JC, Martín M, Amador R, et al. Relative value of magnetic resonance spectroscopy, magnetic resonance perfusion, and 2-(18F) fluoro-2-deoxy-D-glucose positron emission tomography for detection of recurrence or grade increase in gliomas. J Clin Neurosci (2010) 17:50-3. doi:10.1016/j.jocn.2009.02.035

84. McKnight TR, von dem Bussche MH, Vigneron DB, Lu Y, Berger MS, McDermott MW, et al. Histopathological validation of a three-dimensional magnetic resonance spectroscopy index as a predictor of tumor presence. J Neurosurg (2002) 97:794-802. doi:10.3171/jns.2002.97.4.0794

85. Yang I, Huh NG, Smith ZA, Han SJ, Parsa AT. Distinguishing glioma recurrence from treatment effect after radiochemotherapy and immunotherapy. Neurosurg Clin N Am (2010) 21:181-6. doi:10.1016/j.nec.2009.08.003

86. Rock JP, Scarpace L, Hearshen D, Gutierrez J, Fisher JL, Rosenblum M, et al. Associations among magnetic resonance spectroscopy, apparent diffusion coefficients, and image-guided histopathology with special attention to radiation necrosis. Neurosurgery (2004) 54:1111-7. doi:10.1227/01.NEU.0000119328. 56431.A7

87. Weybright P, Sundgren PC, Maly P, Hassan DG, Nan B, Rohrer S, et al. Differentiation between brain tumor recurrence and radiation injury using MR spectroscopy. AJR Am J Roentgenol (2005) 185:1471-6. doi:10.2214/AJR.04.0933

88. Zeng Q-S, Li C-F, Zhang K, Liu H, Kang X-S, Zhen J-H. Multivoxel 3D proton MR spectroscopy in the distinction of recurrent glioma from radiation injury. J Neurooncol (2007) 84:63-9. doi:10.1007/s11060-007-9341-3

89. Smith EA, Carlos RC, Junck LR, Tsien CI, Elias A, Sundgren PC. Developing a clinical decision model: MR spectroscopy to differentiate between recurrent tumor and radiation change in patients with new contrast-enhancing lesions. AJR Am J Roentgenol (2009) 192:W45-52. doi:10.2214/AJR.07.3934

90. Zhang H, Ma L, Wang Q, Zheng X, Wu C, Xu B-N. Role of magnetic resonance spectroscopy for the differentiation of recurrent glioma from radiation necrosis: a systematic review and meta-analysis. Eur J Radiol (2014) 83:2181-9. doi:10.1016/j.ejrad.2014.09.018

91. Estève F, Rubin C, Grand S, Kolodié H, Le Bas JF. Transient metabolic changes observed with proton MR spectroscopy in normal human brain after radiation therapy. Int J Radiat Oncol Biol Phys (1998) 40:279-86. doi:10.1016/S03603016(97)00714-1

92. Kaminaga T, Shirai K. Radiation-induced brain metabolic changes in the acute and early delayed phase detected with quantitative proton magnetic resonance spectroscopy. J Comput Assist Tomogr (2005) 29:293-7. doi:10.1097/01.rct. $0000161422.95625 .8 \mathrm{a}$

93. Di Chiro G, DeLaPaz RL, Brooks RA, Sokoloff L, Kornblith PL, Smith BH, et al. Glucose utilization of cerebral gliomas measured by [ $18 \mathrm{~F}]$ fluorodeoxyglucose and positron emission tomography. Neurology (1982) 32:1323-9. doi:10.1212/ WNL.32.12.1323

94. Kincaid PK, El-Saden SM, Park SH, Goy BW. Cerebral gangliogliomas: preoperative grading using FDG-PET and 201Tl-SPECT. AJNR Am J Neuroradiol (1998) 19:801-6.

95. Delbeke D, Meyerowitz C, Lapidus RL, Maciunas RJ, Jennings MT, Moots PL, et al. Optimal cutoff levels of F-18 fluorodeoxyglucose uptake in the differentiation of low-grade from high-grade brain tumors with PET. Radiology (1995) 195:47-52. doi:10.1148/radiology.195.1.7892494

96. Di Chiro G. Positron emission tomography using [ $18 \mathrm{~F}]$ fluorodeoxyglucose in brain tumors. A powerful diagnostic and prognostic tool. Invest Radiol (1987) 22:360-71. doi:10.1097/00004424-198705000-00002

97. Hustinx R, Smith RJ, Benard F, Bhatnagar A, Alavi A. Can the standardized uptake value characterize primary brain tumors on FDG-PET? Eur J Nucl Med (1999) 26:1501-9. doi:10.1007/s002590050487

98. Kosaka N, Tsuchida T, Uematsu H, Kimura H, Okazawa H, Itoh H. 18F-FDG PET of common enhancing malignant brain tumors. AJR Am J Roentgenol (2008) 190:W365-9. doi:10.2214/AJR.07.2660

99. De Witte O, Lefranc F, Levivier M, Salmon I, Brotchi J, Goldman S. FDG-PET as a prognostic factor in high-grade astrocytoma. J Neurooncol (2000) 49:157-63. doi:10.1023/A:1026518002800
100. Pardo FS, Aronen HJ, Fitzek M, Kennedy DN, Efird J, Rosen BR, et al. Correlation of FDG-PET interpretation with survival in a cohort of glioma patients. Anticancer Res (2004) 24:2359-65.

101. Tralins KS, Douglas JG, Stelzer KJ, Mankoff DA, Silbergeld DL, Rostomily RC, et al. Volumetric analysis of $18 F$-FDG PET in glioblastoma multiforme: prognostic information and possible role in definition of target volumes in radiation dose escalation. J Nucl Med (2002) 43:1667-73.

102. Spence AM, Muzi M, Graham MM, O’Sullivan F, Link JM, Lewellen TK, et al. 2[(18)F]Fluoro-2-deoxyglucose and glucose uptake in malignant gliomas before and after radiotherapy: correlation with outcome. Clin Cancer Res (2002) 8:971-9.

103. Kelloff GJ, Hoffman JM, Johnson B, Scher HI, Siegel BA, Cheng EY, et al. Progress and promise of FDG-PET imaging for cancer patient management and oncologic drug development. Clin Cancer Res (2005) 11:2785-808. doi:10.1158/1078-0432.CCR-04-2626

104. Kim YH, Oh SW, Lim YJ, Park C-K, Lee S-H, Kang KW, et al. Differentiating radiation necrosis from tumor recurrence in high-grade gliomas: assessing the efficacy of $18 F$-FDG PET, $11 C$-methionine PET and perfusion MRI. Clin Neurol Neurosurg (2010) 112:758-65. doi:10.1016/j.clineuro.2010.06.005

105. Gómez-Río M, Rodríguez-Fernández A, Ramos-Font C, López-Ramírez E, Llamas-Elvira JM. Diagnostic accuracy of 201Thallium-SPECT and $18 F$-FDGPET in the clinical assessment of glioma recurrence. Eur J Nucl Med Mol Imaging (2008) 35:966-75. doi:10.1007/s00259-007-0661-5

106. Ricci PE, Karis JP, Heiserman JE, Fram EK, Bice AN, Drayer BP. Differentiating recurrent tumor from radiation necrosis: time for re-evaluation of positron emission tomography? AJNR Am J Neuroradiol (1998) 19:407-13.

107. Di Chiro G, Oldfield E, Wright DC, De Michele D, Katz DA, Patronas NJ, et al. Cerebral necrosis after radiotherapy and/or intraarterial chemotherapy for brain tumors: PET and neuropathologic studies. AJR Am J Roentgenol (1988) 150:189-97. doi:10.2214/ajr.150.1.189

108. Valk PE, Budinger TF, Levin VA, Silver P, Gutin PH, Doyle WK. PET of malignant cerebral tumors after interstitial brachytherapy. Demonstration of metabolic activity and correlation with clinical outcome. J Neurosurg (1988) 69:830-8. doi:10.3171/jns.1988.69.6.0830

109. Spence AM, Muzi M, Mankoff DA, O’Sullivan SF, Link JM, Lewellen TK, et al. $18 F$-FDG PET of gliomas at delayed intervals: improved distinction between tumor and normal gray matter. J Nucl Med (2004) 45:1653-9.

110. Horky LL, Hsiao EM, Weiss SE, Drappatz J, Gerbaudo VH. Dual phase FDGPET imaging of brain metastases provides superior assessment of recurrence versus post-treatment necrosis. J Neurooncol (2011) 103:137-46. doi:10.1007/ s11060-010-0365-8

111. Padma MV, Said S, Jacobs M, Hwang DR, Dunigan K, Satter M, et al. Prediction of pathology and survival by FDG PET in gliomas. J Neurooncol (2003) 64:227-37. doi:10.1023/A:1025665820001

112. Kubota R, Yamada S, Kubota K, Ishiwata K, Tamahashi N, Ido T. Intratumoral distribution of fluorine-18-fluorodeoxyglucose in vivo: high accumulation in macrophages and granulation tissues studied by microautoradiography. J Nucl Med (1992) 33:1972-80.

113. Isselbacher KJ. Sugar and amino acid transport by cells in culture - differences between normal and malignant cells. N Engl J Med (1972) 286:929-33. doi:10.1056/NEJM197204272861707

114. Busch H, Davis JR, Honig GR, Anderson DC, Nair PV, Nyhan WL. The uptake of a variety of amino acids into nuclear proteins of tumors and other tissues. Cancer Res (1959) 19:1030-9.

115. Kato T, Shinoda J, Oka N, Miwa K, Nakayama N, Yano H, et al. Analysis of $11 C$ methionine uptake in low-grade gliomas and correlation with proliferative activity. AJNR Am J Neuroradiol (2008) 29:1867-71. doi:10.3174/ajnr.A1242

116. Sato N, Suzuki M, Kuwata N, Kuroda K, Wada T, Beppu T, et al. Evaluation of the malignancy of glioma using $11 C$-methionine positron emission tomography and proliferating cell nuclear antigen staining. Neurosurg Rev (1999) 22:210-4. doi:10.1007/s101430050018

117. Bergström M, Collins VP, Ehrin E, Ericson K, Eriksson L, Greitz T, et al. Discrepancies in brain tumor extent as shown by computed tomography and positron emission tomography using [68Ga]EDTA, [11C]glucose, and [11C]methionine. J Comput Assist Tomogr (1983) 7:1062-6. doi:10.1097/ 00004728-198312000-00022

118. Ericson K, Lilja A, Bergström M, Collins VP, Eriksson L, Ehrin E, et al. Positron emission tomography with ([11C]methyl)-L-methionine, $[11 C]$ 
D-glucose, and [68Ga]EDTA in supratentorial tumors. J Comput Assist Tomogr (1985) 9:683-9. doi:10.1097/00004728-198507010-00005

119. Lilja A, Bergström K, Hartvig P, Spännare B, Halldin C, Lundqvist H, et al. Dynamic study of supratentorial gliomas with L-methyl-11C-methionine and positron emission tomography. AJNR Am J Neuroradiol (1985) 6:505-14.

120. De Witte O, Goldberg I, Wikler D, Rorive S, Damhaut P, Monclus M, et al. Positron emission tomography with injection of methionine as a prognostic factor in glioma. J Neurosurg (2001) 95:746-50. doi:10.3171/jns. 2001.95.5.0746

121. Li D-L, Xu Y-K, Wang Q-S, Wu H-B, Li H-S. ${ }^{11} \mathrm{C}$-methionine and ${ }^{18} \mathrm{~F}$ fluorodeoxyglucose positron emission tomography/CT in the evaluation of patients with suspected primary and residual/recurrent gliomas. Chin Med $J$ (Engl) (2012) 125:91-6.

122. Van Laere K, Ceyssens S, Van Calenbergh F, de Groot T, Menten J, Flamen P, et al. Direct comparison of $18 F$-FDG and $11 C$-methionine PET in suspected recurrence of glioma: sensitivity, inter-observer variability and prognostic value. Eur J Nucl Med Mol Imaging (2005) 32:39-51. doi:10.1007/s00259-004-1564-3

123. Chung J-K, Kim YK, Kim S, Lee YJ, Paek S, Yeo JS, et al. Usefulness of $11 C$ methionine PET in the evaluation of brain lesions that are hypo- or isometabolic on 18F-FDG PET. Eur J Nucl Med Mol Imaging (2002) 29:176-82. doi:10.1007/s00259-001-0690-4

124. Go KG, Keuter EJ, Kamman RL, Pruim J, Metzemaekers JD, Staal MJ, et al. Contribution of magnetic resonance spectroscopic imaging and L[1-11C]tyrosine positron emission tomography to localization of cerebral gliomas for biopsy. Neurosurgery (1994) 34:994-1002. doi:10.1227/00006123199406000-00007

125. Willemsen AT, van Waarde A, Paans AM, Pruim J, Luurtsema G, Go KG, et al. In vivo protein synthesis rate determination in primary or recurrent brain tumors using L-[1-11C]-tyrosine and PET. J Nucl Med (1995) 36:411-9.

126. Heesters MA, Go KG, Kamman RL, Mooyaart EL, Meertens H, Paans AM, et al. $11 \mathrm{C}$-tyrosine position emission tomography and $1 \mathrm{H}$ magnetic resonance spectroscopy of the response of brain gliomas to radiotherapy. Neuroradiology (1998) 40:103-8. doi:10.1007/s002340050548

127. Ullrich R, Backes H, Li H, Kracht L, Miletic H, Kesper K, et al. Glioma proliferation as assessed by 3'-fluoro-3'-deoxy-L-thymidine positron emission tomography in patients with newly diagnosed high-grade glioma. Clin Cancer Res (2008) 14:2049-55. doi:10.1158/1078-0432.CCR-07-1553

128. Schiepers C, Dahlbom M, Chen W, Cloughesy T, Czernin J, Phelps ME, et al. Kinetics of 3'-deoxy-3'-18F-fluorothymidine during treatment monitoring of recurrent high-grade glioma. J Nucl Med (2010) 51:720-7. doi:10.2967/ jnumed.109.068361

129. Muzi M, Spence AM, O'Sullivan F, Mankoff DA, Wells JM, Grierson JR, et al. Kinetic analysis of 3'-deoxy-3'-18F-fluorothymidine in patients with gliomas. J Nucl Med (2006) 47:1612-21.

130. Spence AM, Muzi M, Link JM, O'Sullivan F, Eary JF, Hoffman JM, et al. NCIsponsored trial for the evaluation of safety and preliminary efficacy of 3'deoxy-3'-[18F]fluorothymidine (FLT) as a marker of proliferation in patients with recurrent gliomas: preliminary efficacy studies. Mol Imaging Biol (2009) 11:343-55. doi:10.1007/s11307-009-0215-2

131. Pöpperl G, Götz C, Rachinger W, Gildehaus F-J, Tonn J-C, Tatsch K. Value of $O$ (2-[18F]fluoroethyl)-L-tyrosine PET for the diagnosis of recurrent glioma. Eur J Nucl Med Mol Imaging (2004) 31:1464-70. doi:10.1007/s00259-004-1590-1

132. Pauleit D, Floeth F, Hamacher K, Riemenschneider MJ, Reifenberger G, Müller H-W, et al. $O-(2-[18 F]$ fluoroethyl)-L-tyrosine PET combined with MRI improves the diagnostic assessment of cerebral gliomas. Brain (2005) 128:678-87. doi:10.1093/brain/awh399

133. Rachinger W, Goetz C, Pöpperl G, Gildehaus FJ, Kreth FW, Holtmannspötter M, et al. Positron emission tomography with $O$-(2-[18F]fluoroethyl)-L-tyrosine versus magnetic resonance imaging in the diagnosis of recurrent gliomas. Neurosurgery (2005) 57:505-11. doi:10.1227/01.NEU.0000171642.49553.B0

134. Dunet V, Rossier C, Buck A, Stupp R, Prior JO. Performance of $18 F$-fluoroethyl-tyrosine (18F-FET) PET for the differential diagnosis of primary brain tumor: a systematic review and Metaanalysis. J Nucl Med (2012) 53:207-14. doi:10.2967/jnumed.111.096859

135. Weber WA, Wester HJ, Grosu AL, Herz M, Dzewas B, Feldmann HJ, et al. O-(2$[18 F]$ fluoroethyl)-L-tyrosine and $\mathrm{L}$-[methyl-11C]methionine uptake in brain tumours: initial results of a comparative study. Eur J Nucl Med (2000) 27:542-9. doi:10.1007/s002590050541
136. Heiss WD, Wienhard K, Wagner R, Lanfermann H, Thiel A, Herholz K, et al. F-Dopa as an amino acid tracer to detect brain tumors. J Nucl Med (1996) 37:1180-2.

137. Becherer A, Karanikas G, Szabó M, Zettinig G, Asenbaum S, Marosi C, et al. Brain tumour imaging with PET: a comparison between [18F]fluorodopa and [11C]methionine. Eur J Nucl Med Mol Imaging (2003) 30:1561-7. doi:10.1007/s00259-003-1259-1

138. Schiepers C, Chen W, Cloughesy T, Dahlbom M, Huang S-C. 18F-FDOPA kinetics in brain tumors. J Nucl Med (2007) 48:1651-61. doi:10.2967/jnumed. 106.039321

139. Fueger BJ, Czernin J, Cloughesy T, Silverman DH, Geist CL, Walter MA, et al. Correlation of 6-18F-fluoro-L-dopa PET uptake with proliferation and tumor grade in newly diagnosed and recurrent gliomas. J Nucl Med (2010) 51:1532-8. doi:10.2967/jnumed.110.078592

140. Ledezma CJ, Chen W, Sai V, Freitas B, Cloughesy T, Czernin J, et al. 18F-FDOPA PET/MRI fusion in patients with primary/recurrent gliomas: initial experience. Eur J Radiol (2009) 71:242-8. doi:10.1016/j.ejrad.2008.04.018

141. Chen W, Silverman DHS, Delaloye S, Czernin J, Kamdar N, Pope W, et al. 18FFDOPA PET imaging of brain tumors: comparison study with $18 F$-FDG PET and evaluation of diagnostic accuracy. J Nucl Med (2006) 47:904-11.

142. Oborski MJ, Demirci E, Laymon CM, Lieberman FS, Mountz JM. Assessment of early therapy response with 18 -FLT PET in glioblastoma multiforme. Clin Nucl Med (2014) 39:e431-2. doi:10.1097/RLU.0000000000000321

143. Galldiks N, Langen K-J, Holy R, Pinkawa M, Stoffels G, Nolte KW, et al. Assessment of treatment response in patients with glioblastoma using $\mathrm{O}-(2-$ 18 F-fluoroethyl)-L-tyrosine PET in comparison to MRI. J Nucl Med (2012) 53:1048-57. doi:10.2967/jnumed.111.098590

144. Piroth MD, Pinkawa M, Holy R, Klotz J, Nussen S, Stoffels G, et al. Prognostic value of early $[18 F]$ fluoroethyltyrosine positron emission tomography after radiochemotherapy in glioblastoma multiforme. Int J Radiat Oncol Biol Phys (2011) 80:176-84. doi:10.1016/j.ijrobp.2010.01.055

145. Batchelor TT, Duda DG, di Tomaso E, Ancukiewicz M, Plotkin SR, Gerstner E, et al. Phase II study of cediranib, an oral pan-vascular endothelial growth factor receptor tyrosine kinase inhibitor, in patients with recurrent glioblastoma. J Clin Oncol (2010) 28:2817-23. doi:10.1200/JCO.2009.26.3988

146. Batchelor TT, Sorensen AG, di Tomaso E, Zhang W-T, Duda DG, Cohen KS, et al. AZD2171, a pan-VEGF receptor tyrosine kinase inhibitor, normalizes tumor vasculature and alleviates edema in glioblastoma patients. Cancer Cell (2007) 11:83-95. doi:10.1016/j.ccr.2006.11.021

147. Norden AD, Drappatz J, Muzikansky A, David K, Gerard M, McNamara MB, et al. An exploratory survival analysis of anti-angiogenic therapy for recurrent malignant glioma. J Neurooncol (2009) 92:149-55. doi:10.1007/s11060-0089745-8

148. Melhem ER, Mehta NR. Dynamic T1-weighted spin-echo MR imaging: the role of digital subtraction in the demonstration of enhancing brain lesions. J Magn Reson Imaging (1999) 9:503-8. doi:10.1002/(SICI)1522-2586(199904) 9:4<503::AID-JMRI1 >3.0.CO;2-0

149. Kanaly CW, Ding D, Mehta AI, Waller AF, Crocker I, Desjardins A, et al. A novel method for volumetric MRI response assessment of enhancing brain tumors. PLoS One (2011) 6:e16031. doi:10.1371/journal.pone.0016031

150. Ellingson BM, Kim HJ, Woodworth DC, Pope WB, Cloughesy JN, Harris RJ, et al. Recurrent glioblastoma treated with bevacizumab: contrast-enhanced T1-weighted subtraction maps improve tumor delineation and aid prediction of survival in a multicenter clinical trial. Radiology (2014) 271:200-10. doi:10.1148/radiol.13131305

151. Ellingson BM, Cloughesy TF, Lai A, Nghiemphu PL, Lalezari S, Zaw T, et al. Quantification of edema reduction using differential quantitative T2 (DQT2) relaxometry mapping in recurrent glioblastoma treated with bevacizumab. J Neurooncol (2012) 106(1):111-9. doi:10.1007/s11060-011-0638-x

152. Hattingen E, Jurcoane A, Daneshvar K, Pilatus U, Mittelbronn M, Steinbach JP, et al. Quantitative T2 mapping of recurrent glioblastoma under bevacizumab improves monitoring for non-enhancing tumor progression and predicts overall survival. Neuro Oncol (2013) 15:1395-404. doi:10.1093/neuonc/not105

153. Jalali S, Chung C, Foltz W, Burrell K, Singh S, Hill R, et al. MRI biomarkers identify the differential response of glioblastoma multiforme to anti-angiogenic therapy. Neuro Oncol (2014) 16:868-79. doi:10.1093/neuonc/nou040

154. Pope WB, Kim HJ, Huo J, Alger J, Brown MS, Gjertson D, et al. Recurrent glioblastoma multiforme: ADC histogram analysis predicts response 
to bevacizumab treatment. Radiology (2009) 252:182-9. doi:10.1148/radiol. 2521081534

155. Pope WB, Qiao XJ, Kim HJ, Lai A, Nghiemphu P, Xue X, et al. Apparent diffusion coefficient histogram analysis stratifies progression-free and overall survival in patients with recurrent GBM treated with bevacizumab: a multi-center study. J Neurooncol (2012) 108:491-8. doi:10.1007/s11060-012-0847-y

156. Rahman R, Hamdan A, Zweifler R, Jiang H, Norden AD, Reardon DA, et al. Histogram analysis of apparent diffusion coefficient within enhancing and nonenhancing tumor volumes in recurrent glioblastoma patients treated with bevacizumab. J Neurooncol (2014) 119:149-58. doi:10.1007/s11060-0141464-8

157. Nowosielski M, Recheis W, Goebel G, Güler O, Tinkhauser G, Kostron $\mathrm{H}$, et al. ADC histograms predict response to anti-angiogenic therapy in patients with recurrent high-grade glioma. Neuroradiology (2011) 53:291-302. doi:10.1007/s00234-010-0808-0

158. Ellingson BM, Cloughesy TF, Lai A, Mischel PS, Nghiemphu PL, Lalezari S, et al. Graded functional diffusion map-defined characteristics of apparent diffusion coefficients predict overall survival in recurrent glioblastoma treated with bevacizumab. Neuro Oncol (2011) 13:1151-61. doi:10.1093/neuonc/nor079

159. Ellingson BM, LaViolette PS, Rand SD, Malkin MG, Connelly JM, Mueller WM, et al. Spatially quantifying microscopic tumor invasion and proliferation using a voxel-wise solution to a glioma growth model and serial diffusion MRI. Magn Reson Med (2011) 65:1131-43. doi:10.1002/mrm.22688

160. Gerstner ER, Chen P-J, Wen PY, Jain RK, Batchelor TT, Sorensen G. Infiltrative patterns of glioblastoma spread detected via diffusion MRI after treatment with cediranib. Neuro Oncol (2010) 12:466-72. doi:10.1093/neuonc/nop051

161. Jain R, Scarpace LM, Ellika S, Torcuator R, Schultz LR, Hearshen D, et al. Imaging response criteria for recurrent gliomas treated with bevacizumab: role of diffusion weighted imaging as an imaging biomarker. J Neurooncol (2010) 96:423-31. doi:10.1007/s11060-009-9981-6

162. Seo HS, Chang KH, Na DG, Kwon BJ, Lee DH. High b-value diffusion ( $b=$ $3000 \mathrm{~s} / \mathrm{mm}^{2}$ ) MR imaging in cerebral gliomas at 3T: visual and quantitative comparisons with $\mathrm{b}=1000 \mathrm{~s} / \mathrm{mm}^{2}$. AJNR Am J Neuroradiol (2008) 29:458-63. doi:10.3174/ajnr.A0842

163. Kang Y, Choi SH, Kim Y-J, Kim KG, Sohn C-H, Kim J-H, et al. Gliomas: histogram analysis of apparent diffusion coefficient maps with standard- or high-b-value diffusion-weighted MR imaging - correlation with tumor grade. Radiology (2011) 261:882-90. doi:10.1148/radiol.11110686

164. Yamasaki F, Kurisu K, Aoki T, Yamanaka M, Kajiwara Y, Watanabe Y, et al. Advantages of high b-value diffusion-weighted imaging to diagnose pseudoresponses in patients with recurrent glioma after bevacizumab treatment. Eur J Radiol (2012) 81(10):2805-10. doi:10.1016/j.ejrad.2011.10.018

165. Sorensen AG, Batchelor TT, Zhang W-T, Chen P-J, Yeo P, Wang M, et al. A "vascular normalization index" as potential mechanistic biomarker to predict survival after a single dose of cediranib in recurrent glioblastoma patients. Cancer Res (2009) 69:5296-300. doi:10.1158/0008-5472.CAN-09-0814

166. Batchelor TT, Gerstner ER, Emblem KE, Duda DG, Kalpathy-Cramer J, Snuderl $\mathrm{M}$, et al. Improved tumor oxygenation and survival in glioblastoma patients who show increased blood perfusion after cediranib and chemoradiation. Proc Natl Acad Sci U S A (2013) 110:19059-64. doi:10.1073/pnas.1318022110

167. Jain RK. Normalization of tumor vasculature: an emerging concept in antiangiogenic therapy. Science (2005) 307:58-62. doi:10.1126/science.1104819

168. Essock-Burns E, Lupo JM, Cha S, Polley M-Y, Butowski NA, Chang SM, et al. Assessment of perfusion MRI-derived parameters in evaluating and predicting response to antiangiogenic therapy in patients with newly diagnosed glioblastoma. Neuro Oncol (2011) 13:119-31. doi:10.1093/neuonc/noq143

169. Jain R, Gutierrez J, Narang J, Scarpace L, Schultz LR, Lemke N, et al. In vivo correlation of tumor blood volume and permeability with histologic and molecular angiogenic markers in gliomas. AJNR Am J Neuroradiol (2011) 32:388-94. doi:10.3174/ajnr.A2280

170. Schmainda KM, Prah M, Connelly J, Rand SD, Hoffman RG, Mueller W, et al. Dynamic-susceptibility contrast agent MRI measures of relative cerebral blood volume predict response to bevacizumab in recurrent high-grade glioma. Neuro Oncol (2014) 16:880-8. doi:10.1093/neuonc/not216

171. Hodi FS, O'Day SJ, McDermott DF, Weber RW, Sosman JA, Haanen JB, et al. Improved survival with ipilimumab in patients with metastatic melanoma. N Engl J Med (2010) 363:711-23. doi:10.1056/NEJMoa1003466

172. Kantoff PW, Higano CS, Shore ND, Berger ER, Small EJ, Penson DF, et al. Sipuleucel-T immunotherapy for castration-resistant prostate cancer. $N$ Engl J Med (2010) 363:411-22. doi:10.1056/NEJMoa1001294

173. Wolchok JD, Hoos A, O’Day S, Weber JS, Hamid O, Lebbé C, et al. Guidelines for the evaluation of immune therapy activity in solid tumors: immune-related response criteria. Clin Cancer Res (2009) 15:7412-20. doi:10.1158/1078-0432. CCR-09-1624

174. Camacho LH, Antonia S, Sosman J, Kirkwood JM, Gajewski TF, Redman B, et al. Phase I/II trial of tremelimumab in patients with metastatic melanoma. J Clin Oncol (2009) 27:1075-81. doi:10.1200/JCO.2008.19.2435

175. Weber JS, O’Day S, Urba W, Powderly J, Nichol G, Yellin M, et al. Phase I/II study of ipilimumab for patients with metastatic melanoma. J Clin Oncol (2008) 26:5950-6. doi:10.1200/JCO.2008.16.1927

176. Okada H, Pollack IF. Do we need novel radiologic response criteria for brain tumor immunotherapy? Expert Rev Neurother (2011) 11:619-22. doi:10.1586/ ern.11.49

177. Floeth FW, Wittsack HJ, Engelbrecht V, Weber F. Comparative follow-up of enhancement phenomena with MRI and proton MR spectroscopic imaging after intralesional immunotherapy in glioblastoma - report of two exceptional cases. Zentralbl Neurochir (2002) 63:23-8. doi:10.1055/s-2002-31579

178. Pollack IF, Jakacki RI, Butterfield LH, Hamilton RL, Panigrahy A, Potter DM, et al. Antigen-specific immune responses and clinical outcome after vaccination with glioma-associated antigen peptides and polyinosinic-polycytidylic acid stabilized by lysine and carboxymethylcellulose in children with newly diagnosed malignant brainstem and nonbrainstem gliomas. J Clin Oncol (2014) 32:2050-8. doi:10.1200/JCO.2013.54.0526

179. Vrabec M, Van Cauter S, Himmelreich U, Van Gool SW, Sunaert S, De Vleeschouwer $S$, et al. MR perfusion and diffusion imaging in the follow-up of recurrent glioblastoma treated with dendritic cell immunotherapy: a pilot study. Neuroradiology (2011) 53:721-31. doi:10.1007/s00234-010-0802-6

Conflict of Interest Statement: The authors declare that the research was conducted in the absence of any commercial or financial relationships that could be construed as a potential conflict of interest.

Received: 24 October 2014; paper pending published: 18 November 2014; accepted: 09 February 2015; published online: 23 February 2015.

Citation: Huang RY, Neagu MR, Reardon DA and Wen PY (2015) Pitfalls in the neuroimaging of glioblastoma in the era of antiangiogenic and immuno/targeted therapy - detecting illusive disease, defining response. Front. Neurol. 6:33. doi: 10.3389/fneur.2015.00033

This article was submitted to Neuro-Oncology, a section of the journal Frontiers in Neurology.

Copyright $\odot 2015$ Huang, Neagu, Reardon and Wen. This is an open-access article distributed under the terms of the Creative Commons Attribution License (CC BY). The use, distribution or reproduction in other forums is permitted, provided the original author(s) or licensor are credited and that the original publication in this journal is cited, in accordance with accepted academic practice. No use, distribution or reproduction is permitted which does not comply with these terms. 